\title{
¿CÓMO PUEDE EL DERECHO OBLIGAR A QUIENES OPRIME?
}

\author{
Jorge L. Rodríguez *
}

\section{Introducción}

Hay preguntas cuya formulación paradójica parece resistir todo intento de respuesta. De hecho, muchas de ellas no tienen la pretensión de ser respondidas, al menos directamente, sino que más bien constituyen recursos retóricos provocativos para alertarnos sobre algún problema o para poner al desnudo una contradicción. ${ }^{1}$

En el final de un reciente artículo, Ronald Dworkin exhorta a los jóvenes investigadores a correr el riesgo de ocuparse de las cosas interesantes que, en su criterio, son las normativas, y rechazar la pretendida neutralidad de las meramente conceptuales. ${ }^{2}$ Dworkin sostiene allí, como en trabajos anteriores, que es posible hacer análisis conceptual y, al propio tiempo, normativo. Es más, un análisis meramente conceptual de cuestiones tales como la naturaleza del derecho, la justicia o la igualdad, no sería simplemente poco interesante: sería imposible.

A diferencia de lo que ha sido casi una constante en la mayor parte de mis escritos, asumiré aquí el riesgo al que nos desafía Dworkin, e intentaré examinar las respuestas alternativas que pueden ofrecerse a la pregunta que

\footnotetext{
* Universidad Nacional de Mar del Plata

${ }^{1}$ Cuando escribía esto pensaba en el título del libro de Gerald CoHen Si eres igualitarista, ¿cómo es que eres tan rico? Pero, a diferencia de lo que digo en el texto, la pregunta de COHEN me parece genuina, y de una honestidad intelectual y personal poco frecuentes.

${ }^{2}$ Cf. Dworkin 2004:37.
} 
titula mi contribución, comenzando con un breve análisis conceptual del problema de la autoridad del derecho, para luego presentar mi posición sobre la cuestión normativa que ella plantea. ${ }^{3}$ Sobre esto último, intentaré sostener que el derecho sólo puede crear genuinos deberes, esto es, ofrecer razones para actuar no meramente prudenciales y fundadas únicamente en el temor al descarnado uso de la fuerza, si sus prescripciones consagran un régimen radicalmente igualitario, donde el calificativo "radicalmente" sólo se justifica si se lo entiende como una forma de alertar que semejante régimen está muy lejos de los que hoy se encuentran en vigor. Y ello porque cualquier distribución no igualitaria requiere de una justificación, y ninguna justificación parece plausible para legitimar desigualdades. De manera que, en última instancia, trataré de mostrar que el título de mi trabajo no contiene una pregunta genuina y que debe leérselo como una protesta.

Con todo, quiero aclarar -aunque en realidad ello se sigue de lo que expresé en el párrafo anterior- que si bien cedo al desafío de Dworkin, no concedo lo que su desafío presupone. Diría más: si me atrevo a escribir estas páginas es, entre otras cosas, para tratar de mostrar que nada se puede decir con sentido en el plano normativo si no se efectúan previamente las precisiones conceptuales necesarias.

\section{La paradoja de la autoridad y paradojas afines}

Ninguna explicación satisfactoria de la idea de autoridad puede omitir ofrecer algún tipo de respuesta a lo que podría calificarse como la paradoja

\footnotetext{
${ }^{3}$ La motivación primordial a la que obedece la elaboración del presente trabajo ha sido ofrecer un comentario crítico a la contribución que inicia este volumen de Carlos RosENKRANTZ, con quien me honra polemizar. No obstante, no efectuaré comentarios puntuales en el texto sobre los argumentos que ofrece RosENKRANTZ en apoyo de su posición, y ello debido a que mis diferencias con su enfoque son demasiado profundas. Sólo formularé algunas precisiones en nota vinculando algunos aspectos que se examinan en el cuerpo de mi trabajo con observaciones de RosENKRANTZ.
} 
de la autoridad: si un rasgo constitutivo de la racionalidad práctica está dado por la autonomía, esto es, por el actuar de conformidad con las razones que uno acepta, y si la aceptación de una autoridad implica deponer el propio juicio colocando en su lugar las prescripciones de la autoridad, entonces nunca puede estar justificada la obediencia a una autoridad. Simplificando un tanto lo que Raz llama la tesis de la no diferencia y Nino la paradoja de la irrelevancia moral de la autoridad, podría decirse que si las prescripciones de la autoridad no coinciden con lo que moralmente debe hacerse, dado que siempre ha de hacerse lo moralmente correcto, habría razones para no obedecer tales prescripciones, y si las prescripciones de la autoridad coinciden con lo que moralmente debe hacerse, entonces habrá razones para actuar del modo prescripto, pero que la autoridad lo haya ordenado no sería una de esas razones. ${ }^{4}$ De modo que en ninguno de los dos casos las prescripciones de la autoridad servirían como justificación de las acciones, ya sea por la irracionalidad de su aceptación, ya sea por su irrelevancia.

Existe un conjunto de paradojas vinculadas con ésta, cuya presentación puede ayudarnos a esclarecer la que aquí nos interesa, entre ellas la paradoja del seguimiento de normas generales, la paradoja del procedimiento y el contenido en la toma de decisiones colectivas y la paradoja de Sen del liberal paretiano. Una presentación sintética de la primera de ellas podría efectuarse del siguiente modo: las normas constituyen el significado de oraciones que pueden formularse en el lenguaje para prescribir, esto es, para ordenar, prohibir o permitir genéricamente ciertas acciones. Por su parte, puede interpretarse que una razón para la acción es cualquier factor relevante que cuenta a favor o en contra de la realización de una cierta acción. Decir que algo es una razón para la acción y no conferirle ninguna importancia en el razonamiento práctico para decidir qué se debe hacer equivaldría a no hablar sinceramente o no usar en serio la expresión "razón". ${ }^{5}$ Ahora bien, si las

\footnotetext{
${ }^{4}$ Cf., por todos, BAYÓN 1991a:602-605.

${ }^{5} \mathrm{Cf}$. Redondo 2005.
} 
normas tienen por finalidad básica intentar influir sobre la conducta de sus destinatarios para que hagan o dejen de hacer algo, parecen intuitivamente candidatos ideales para configurar razones para la acción. Es característico de nuestros razonamientos prácticos el acudir a normas de carácter general como premisas para justificar nuestras acciones. Por ejemplo, la norma que obliga a detener la marcha de un vehículo frente a un semáforo en rojo constituye, conjuntamente con la existencia en cierto lugar de un semáforo en rojo, una razón para que detenga la marcha de mi auto (una razón que puede no ser concluyente, pero razón al fin).

No obstante esta conexión aparentemente simple y directa, el que las normas puedan constituir razones para la acción y, en términos más generales, las relaciones existentes entre ambas nociones, son problemas que han generado fuertes controversias en el ámbito de la filosofía moral y de la filosofía jurídica. Porque el uso de normas generales para orientar nuestras acciones parece, al menos a primera vista, sujeto a un problema fundamental: el de la justificación racional en el seguimiento de normas. Una norma general destaca como relevantes ciertas circunstancias para calificar normativamente una acción como obligatoria, prohibida o permitida ("deténgase frente a un semáforo en rojo”). Pero, al hacerlo, necesariamente soslaya la relevancia de otras muchas circunstancias (¿debo detenerme frente a un semáforo en rojo si estoy llevando a mi esposa de urgencia al hospital para dar a luz?). Y en cierto sentido, parecería que la evaluación de lo que debemos hacer en determinada situación requiere tomar en cuenta todo posible factor que pudiese tener incidencia en la determinación de nuestras obligaciones, esto es, que debe atenderse al espectro completo de razones en juego. Pero si las normas se interpretan y aplican como si fuesen completamente "transparentes" respecto de nuestra evaluación del resultado que ofrece el balance de todas las razones en juego en cada caso, esto es, si en cada situación de posible discordancia entre lo que expresa una norma y el balance completo de las razones en juego ha de estarse al resultado de este último, las normas como tales resultarían herramientas inútiles. Así, el uso de normas para la resolución 
de problemas prácticos parece conducir al siguiente dilema: o aceptamos la orientación que ellas nos ofrecen, lo cual resultaría en última instancia una forma de descalificación por anticipado de ciertos factores potencialmente relevantes en la dilucidación de lo que se debe hacer y, consiguientemente, una forma de irracionalidad, o dejamos de lado la guía que ofrecen las normas y nos concentramos en lo particular de cada situación para decidir cómo actuar de conformidad con el plexo completo de razones en juego, con lo que las normas se tornan irrelevantes.

La paradoja que suscita la consideración del procedimiento y el contenido en la toma de decisiones colectivas pone de manifiesto una tensión entre estos dos aspectos que parece difícil de resolver. Por un lado, tenemos la intuición de que la legitimidad de una decisión política exige que ella haya sido tomada mediante cierto tipo de procedimiento; pero, por otro lado, nuestras intuiciones se resisten a desvincular completamente la legitimidad de una decisión política de la justicia de su contenido. ${ }^{6}$ Ahora bien, aunque existen fuertes razones para tomar en consideración ambos aspectos en el examen de legitimidad de las decisiones políticas, si una decisión política se juzga como legítima en función del procedimiento empleado para alcanzarla, cuando se sigue el procedimiento correcto, la decisión debería aceptarse como legítima con independencia de su contenido, esto es, el contenido parece irrelevante. Y si en cambio no se está dispuesto a calificarla como legítima si su contenido es injusto, ello parece indicar que seguir cierto procedimiento puede arrojar resultados irracionales.

La paradoja del liberal paretiano desarrollada por Amartya Sen puede esquematizarse del siguiente modo. Supóngase que se pretende determinar las preferencias de un grupo de personas a partir de las preferencias de sus miembros de manera tal que el mecanismo de decisión colectiva determine una preferencia social para cualquier conjunto de preferencias individuales

${ }^{6}$ Para un reciente y muy inteligente análisis de esta paradoja, véase MARTí 2004. 
lógicamente posible (condición de dominio irrestricto). Supóngase además que asumimos el siguiente principio, conocido como principio de Pareto débil: si todos los individuos prefieren estrictamente $x$ a $y$, entonces $y$ no integrará el conjunto de elección ${ }^{7}$ de la sociedad cuando $x$ se encuentre disponible. Supóngase finalmente que estamos dispuestos a reconocer a cada individuo un ámbito mínimo de libertad en el siguiente sentido: si hay al menos dos individuos $a$ y $b, \mathrm{y}$ dos pares distintos de alternativas $\{x, y\}$ y $\{z, w\}$, si $x \mathrm{P} y$ (si $a$ prefiere en sentido estricto la alternativa $x$ a la alternativa $y$ ), entonces $y$ no pertenece al conjunto de elección de la sociedad cuando $x$ se encuentra disponible, y si $z \mathrm{P} w$ (si $b$ prefiere en sentido estricto la alternativa $z$ a la alternativa $w$ ), entonces $w$ no pertenece al conjunto de elección de la sociedad cuando $z$ se encuentra disponible (en otras palabras, las preferencias de cada individuo son decisivas al menos para un par de alternativas). Pese a la aparente plausibilidad y debilidad de estas condiciones, de conformidad con la demostración de Sen este principio de asignación de derechos, en conjunción con el principio de Pareto débil y la condición de dominio irrestricto, producen una contradicción. ${ }^{8}$

En la presentación que he efectuado he tratado de enfatizar las similitudes entre estas cuatro paradojas. Sin embargo, no creo que los caminos adecuados para solucionarlas resulten uniformes. Una paradoja es una conclusión aparentemente inaceptable derivada mediante un razonamiento aparentemente aceptable de premisas aparentemente aceptables. ${ }^{9}$ Por consiguiente, solucionar una paradoja requiere mostrar que las premisas no son realmente plausibles pese a su apariencia, o que la conclusión es plausible pese a su apariencia, o que el razonamiento empleado no es plausible pese a las apariencias.

\footnotetext{
${ }^{7}$ Un elemento $x$ de un conjunto $\mathrm{X}$ es un mejor elemento de $\mathrm{X}$ con respecto a una relación D si $\mathrm{y}$ sólo si, para todo elemento $y$ de $\mathrm{X}, x \mathrm{D} y$. Un conjunto de elección de $\mathrm{X}$ con respecto a la relación $\mathrm{D}$ es el conjunto de los mejores elementos de X determinados por D. Sigo aquí, tanto en estas definiciones como en la formulación de la paradoja, la presentación de ZULETA 1998:55-73.

${ }^{8}$ Cf. Sen 1970:cap. 6*.

${ }^{9} \mathrm{Cf}$. Sainsbury 1995:1.
} 
La paradoja del liberal paretiano es la que posee la formulación más rigurosa. Por otra parte, la demostración que efectúa Sen de su conclusión resulta formalmente impecable. Por ello, las alternativas propuestas para sortear la dificultad que ella plantea han sido, fundamentalmente, debilitar ya sea la condición de libertad, ya sea el principio de Pareto débil. ${ }^{10}$ En otras palabras, la paradoja pone de manifiesto la inconsistencia que resulta de imponer sobre una función de elección social estas dos condiciones, una procedimental (el principio de Pareto) y una sustantiva (la condición de libertad mínima), pese a su aparente debilidad.

En las otras tres paradojas consideradas resulta mucho menos claro que no exista algún tipo de dificultad o ambigüedad en la formulación de las premisas o de sus respectivas conclusiones y, por ello, a diferencia de la paradoja del liberal paretiano, existen caminos de solución consistentes en intentar mostrar que el problema que plantean es sólo aparente, precisando el alcance de las premisas o de la conclusión.

Veamos sucintamente la paradoja de la legitimidad de las decisiones políticas. Ella parece indicar que al evaluar la legitimidad de una decisión política resulta valioso tanto el procedimiento utilizado como su contenido. Pero estos dos valores se encuentran en mutua tensión, una tensión que a primera vista podría hacernos pensar que o bien la legitimidad de las decisiones políticas depende del procedimiento seguido para adoptarlas, en cuyo caso el contenido de la decisión sería irrelevante, o bien depende de consideraciones sustantivas relativas al contenido de la decisión, pero entonces cualquier procedimiento que se utilice puede conducir a resultados inaceptables. Bajo esta manera de presentar el problema parecería que sólo hay dos caminos para su solución: asumir una posición sustantivista radical, según la cual se desprecian las cuestiones procedimentales a la hora de juzgar la legitimidad de una decisión política, o bien una postura procedimentalista radical, según

${ }^{10}$ Cf. Zuleta 1995:63. 
la cual ha de despreciarse toda consideración sustantiva a la hora de juzgar la legitimidad de una decisión política. Y la dificultad está aquí en que cada una de estas dos alternativas choca contra fuertes intuiciones. Por esta razón, lo que sería más sensato es rechazar la dicotomía planteada por esta formulación del problema: no puede ser que o bien la legitimidad dependa exclusivamente de consideraciones procedimentales o exclusivamente de consideraciones sustantivas. Sin embargo, aunque se rechacen las dos posiciones radicales, todavía subsiste una tensión entre los dos ideales. Esto se podría presentar como una nueva formulación del problema: la legitimidad de las decisiones políticas depende de consideraciones procedimentales y sustantivas (ya que hemos aceptado que no puede depender sólo de unas o de las otras); no obstante, aunque ambas cuestiones son relevantes a la hora de examinar la legitimidad de una decisión política, no es posible asignarles igual peso a ambas, de manera que o bien se le asigna prioridad al procedimiento sobre la sustancia (procedimentalismo débil) o bien se le asigna prioridad a la sustancia sobre el procedimiento (sustancialismo débil).

Ahora bien, ¿por qué no podría admitirse calificar como legítima a una decisión política cuando ha sido tomada por el procedimiento adecuado y además su contenido es sustancialmente correcto, dándole así exactamente el mismo valor a los dos ideales? Porque parece que si ha de dársele algún valor a la legitimidad del contenido de las decisiones políticas, ello necesariamente presupone que existe algún criterio para evaluar ese contenido que resulta independiente del procedimiento seguido para adoptar la decisión. ${ }^{11}$ Ahora bien, si se parte de tal presupuesto, entonces podría sostenerse que el procedimiento ocupará un lugar de menor importancia pues no se aceptará como legítima una decisión, aunque haya sido adoptada a través de un procedimiento que reputamos valioso, si su contenido no se condice con ese criterio sustantivo de corrección que suponemos independiente del

\footnotetext{
${ }^{11}$ En cuyo caso no estaremos frente a un supuesto de justicia procesal pura, sino perfecta o
} imperfecta, según la conocida clasificación de RAWLS (cf. RAWLS 1971:74-75). 
procedimiento. ${ }^{12}$ Por supuesto, se podría rechazar que exista un criterio sustantivo de corrección independiente del procedimiento para evaluar el contenido de las decisiones políticas. Pero si ello es así, podría estimarse que las consideraciones sustantivas ocupan un lugar de menor importancia que el procedimiento, porque en última instancia puede haber diferencias de opinión respecto de cuestiones sustantivas y requeriremos de cierto procedimiento para dirimirlas. En otras palabras, o bien se aceptan criterios sustantivos independientes del procedimiento, en cuyo caso las consideraciones procedimentales resultarían secundarias, o bien se rechaza la existencia de criterios sustantivos independientes del procedimiento, en cuyo caso las consideraciones sustantivas serían secundarias.

No obstante las diferentes alternativas de formulación examinadas, creo que esta dificultad no constituye más que un pseudoproblema. ${ }^{13}{ }^{14} \mathrm{Si}$ lo que se está considerando es la toma de decisiones colectivas es preciso reconocer que necesitamos algún procedimiento para adoptar tales decisiones y dirimir nuestras diferencias de criterio. Esto implica que el aspecto básico que deberá tomarse en cuenta para calificar como legítima a una decisión colectiva será procedimental: no estaremos dispuestos a aceptar una decisión como legítima -incluso si su contenido es sustantivamente correcto- si el procedimiento seguido para alcanzarla no es el que juzgamos apropiado. Con todo, esta

\footnotetext{
${ }^{12}$ En otras palabras, si existe un criterio de corrección sustantiva que sea externo y previo al procedimiento, nunca podemos descartar la posibilidad de que el procedimiento no garantice la corrección del resultado, de modo que sobre quien sostenga que el procedimiento garantiza que estamos en presencia de un caso de justicia procesal perfecta pesará una fuerte carga argumentativa.

${ }^{13}$ La paradoja aquí examinada guarda estrecha conexión con otras dos: la paradoja de las críticas contramayoritarias a la democracia constitucional y la paradoja de las precondiciones de la democracia. Estas dos últimas presentan ciertas dificultades específicas que no examinaré aquí. ${ }^{14} \mathrm{Si}$ bien RosenKRanTz estima que la legitimidad de las decisiones políticas no puede juzgarse en términos puramente procedimentales ni en términos puramente sustantivos, no aclara si a su criterio la tensión entre los aspectos procedimentales y los sustantivos constituye un problema genuino o un pseudoproblema y, en cualquier caso, cuál sería la manera adecuada de solucionarlo o disolverlo.
} 
pauta básica puede verse condicionada o limitada por ciertas exigencias sustantivas: si no se sigue el procedimiento adecuado, la decisión no será reputada legítima, pero incluso si se sigue el procedimiento adecuado puede ser que no estemos dispuestos a aceptar la legitimidad de la decisión si es que resulta claramente contraria a ciertas exigencias sustantivas. Llegamos así al núcleo del problema: ¿cómo determinar cuándo una decisión colectiva es "claramente contraria a ciertas exigencias sustantivas" si subsisten diferencias de criterio al respecto? ¿Mediante el propio procedimiento escogido? Esto no puede ser así: si se suman a la consideración exigencias sustantivas, es porque o bien aceptamos que existen pautas de corrección independientes del procedimiento o bien porque convenimos en aplicar el procedimiento con ciertas limitaciones en cuanto al contenido de las decisiones que pueden así adoptarse. Por ello, parece falaz sostener que si el procedimiento conduce a una decisión sustantivamente correcta, el procedimiento es irrelevante, mientras que si conduce a una decisión sustantivamente incorrecta es irracional. Porque tal problema se presentaría si respecto de cualquier decisión fuera siempre posible determinar a priori si es sustantivamente correcta o no, cuando en verdad podría ocurrir que sólo contáramos con criterios aceptados para excluir ciertas decisiones como sustantivamente incorrectas, y un amplio campo de indeterminación respecto de las restantes.

Una forma diferente de explicar la dificultad es la siguiente: ordinariamente se toman como criterios de legitimidad de las decisiones políticas tanto el procedimiento seguido como el contenido de tales decisiones. Por consiguiente, al modo en que procede Caracciolo respecto de los criterios de pertenencia de normas derivadas a un sistema jurídico (una norma pertenece a un sistema jurídico si y sólo si pertenece a él en virtud de haber sido creada de conformidad con lo que disponen otras normas jurídicas (criterio de legalidad) o por ser consecuencia lógica de otras normas jurídicas (criterio de deducibilidad)), ${ }^{15}$ se podrían distinguir cuatro modelos de legitimidad:

${ }^{15}$ Cf. CARAcciolo 1988:58. 
M : Una decisión política es legítima si y sólo si es legítimo el procedimiento seguido para adoptarla.

M : Una decisión política es legítima si y sólo si es legítimo su contenido.

$\mathrm{M}^{2}$ : Una decisión política es legítima si y sólo si es legítimo el procedimiento o el contenido.

M : Una decisión política es legítima si y sólo si es legítimo el procedimiento 4 y el contenido.

De estos cuatro modelos, $\mathrm{M}_{1}$ y $\mathrm{M}$ parecen claramente descalificables como candidatos, debido a que en cada uno ellos, uno de los dos factores que habitualmente se toman como relevantes para considerar legítima una decisión política resultarían irrelevantes. $\mathrm{M}$, por su parte, parece un criterio demasiado débil, puesto que según él se admitirían como legítimas decisiones cuyo contenido es manifiestamente injusto sólo porque han sido tomadas de conformidad con cierto procedimiento, así como decisiones tomadas por medio de un procedimiento injustificable sólo porque su contenido es justo, de manera que esta salida potencia las criticas a $\mathrm{M}_{1}$ y $\mathrm{M}_{2}$. En consecuencia, sólo nos quedaría asumir alguna forma que se corresponda con el modelo $M_{4}$, según el cual cada uno de los dos criterios constituye una condición necesaria y conjuntamente resultan suficientes para determinar la legitimidad de una decisión política. Sin embargo, parece que subsiste cierta tensión o conflicto en admitir conjuntamente ambos criterios. Lo mismo ocurre con el modelo que Caracciolo señala como más adecuado para reconstruir las relaciones de pertenencia de normas a un sistema jurídico. Y la razón por la que esa aparente tensión subsiste es que, en el caso de los criterios de pertenencia de normas a un sistema jurídico, los criterios de legalidad y deducibilidad no son criterios de pertenencia de un mismo tipo de elementos a un único conjunto, sino que cada uno presupone una noción de "sistema jurídico" diferente. El criterio de deducibilidad puede ser admitido como un criterio de pertenencia de normas a un conjunto estáticamente considerado. El criterio de legalidad indica cuándo podemos admitir un cambio de un 
"sistema jurídico" considerado como un conjunto de normas, por otro conjunto que forma parte de una única secuencia, esto es, de un sistema dinámico ("orden jurídico"). En otras palabras, el criterio de legalidad no es, en sentido estricto, un criterio de pertenencia de normas a un sistema jurídico, sino un criterio de evaluación de los actos de promulgación o derogación de normas a fin de determinar si ellos producen o no una modificación admisible respecto de un conjunto de normas anterior. En nuestro caso ocurre algo muy parecido. "Decisión política" es una expresión que sufre de ambigüedad proceso-producto, esto es, puede interpretársela como referida al acto de tomar una decisión o como referida al resultado de ese acto. El conjunto de las "decisiones legítimas" puede, en consecuencia, interpretarse como un conjunto de actos o como un conjunto de resultados de tales actos. En el segundo caso, ese conjunto es un conjunto estático de contenidos. En el primero, se trata más bien de un conjunto dinámico, que podría reconstruirse como una secuencia de conjuntos en el primer sentido, donde la legitimidad del procedimiento indica cuándo se admitirá un nuevo conjunto en la secuencia. Bajo esta reconstrucción, la evaluación de la legitimidad de los contenidos es relativa a cada conjunto estático. La evaluación de la legitimidad del procedimiento, en cambio, es una evaluación de los criterios para admitir que un cierto acto genera un cambio de un conjunto de contenidos decisionales por otro. Si los dos criterios de legitimidad parecen estar en tensión es porque califican como "legítimas" a cosas distintas. Para cualquier evaluación de la legitimidad del acto de tomar una decisión, el contenido de esa decisión es irrelevante; para cualquier evaluación del contenido de una decisión, el procedimiento seguido para adoptarla es irrelevante, pues en cada caso se hace abstracción de un aspecto. El hecho de que para evaluar un cierto sistema institucional ambas cuestiones no puedan ser ignoradas obliga a efectuar una reconstrucción más compleja de la legitimidad, según la cual -como se sugirió en el párrafo anteriorciertos actos decisorios serán descalificados como ilegítimos, pese a haberse 
seguido el procedimiento adecuado, cuando el contenido de la decisión se estime sustantivamente incorrecto. ${ }^{16}$

En el caso de la paradoja del seguimiento de normas generales me parece claro que si en todo caso en que pudiera existir una discrepancia entre lo que exige la norma y su justificación subyacente se optara por la solución que ofrece esta última, la norma como tal se tornaría irrelevante. Por ello, la vía más plausible para salvar la dificultad aquí planteada parece consistir en tratar de mostrar que no es irracional el uso de normas para justificar nuestras acciones y decisiones. De hecho, resulta muy poco claro en qué podría consistir la idea de justificación práctica si se renuncia a la exigencia de universabilidad, esto es, a tratar de manera normativamente similar los casos semejantes. ${ }^{17}$

La dificultad que deviene crucial superar a este respecto es la que postula que, al destacar como relevantes ciertas circunstancias para calificar normativamente una acción como obligatoria, prohibida o permitida, las normas generales necesariamente soslayan la relevancia de otras muchas circunstancias, que podrían tornarse relevantes frente al caso que se evalúa. Pero esta dificultad es sólo aparente: supóngase que una norma general establece la obligatoriedad de realizar el acto $q$ en toda circunstancia en la que se verifica la propiedad $p$. ¿Significa ello que si concurre en un caso $p$ otra propiedad, ella resultará irrelevante? No necesariamente: en primer lugar, aun cuando el conjunto de las propiedades que definen un caso sean consideradas condiciones suficientes para el surgimiento de la solución normativa a él correlacionada, la relevancia de tales propiedades respecto del caso sólo implica la irrelevancia de toda otra propiedad para dicho caso bajo

\footnotetext{
${ }^{16}$ En el caso de las paradojas más específicas de la democracia, a la ambigüedad comentada en el texto debe sumarse la ambigüedad de la noción de "democracia" presupuesta: si por "democracia" se entiende simplemente la aplicación de la regla de la mayoría, cualquier decisión que no se adopte por aplicación de dicha regla no sería “democrática”. Sin embargo, habitualmente presuponemos una noción más fuerte de "democracia", no puramente formal, según la cual no calificaríamos como "democrática" una decisión que, por caso, privara de ciertos derechos elementales a una minoría, aun en caso de que tal decisión se adopte por mayoría de votos. ${ }^{17}$ Cf. BAYÓN 2001.
} 
la hipótesis de consistencia normativa. Si en el ejemplo considerado otra norma general correlaciona una solución lógicamente incompatible (por ejemplo, prohibido q) con todos aquellos casos en los que se presente una cierta propiedad $r$, tal propiedad podría también ser relevante, pero entonces aquellos casos que puedan ser descriptos al mismo tiempo como $p$ y $r$ resultarán inconsistentemente normados.

La consistencia normativa es sin duda un ideal valioso, pero no me parece que existan buenas razones para suponer que las exigencias que imponen dos normas generales no puedan entrar en conflicto. $Y$ en tal supuesto, existen básicamente dos vías para superar la dificultad. De acuerdo con la primera de ellas, la solución consagrada por una de las normas prevalece en todos los casos sobre la solución consagrada por la otra, esto es, reconocemos una preferencia incondicional de una de las normas sobre la otra para todos los casos de conflicto entre ambas. En nuestro ejemplo, podríamos considerar que para todos los casos en los que se verifiquen conjuntamente $p$ y $r$, la solución ha de ser la establecida en la primera norma (esto es, obligatorio $q$ ). No obstante, esto significaría reconocer que la segunda norma en realidad no regula todos los casos $r$, sino sólo un subconjunto de ellos: aquellos en los que no se verifica además $p$. De modo que la segunda norma no resulta completamente irrelevante, sino que su relevancia se ve limitada a ciertos casos (los casos $r$ que no son $p$ ).

De acuerdo con la segunda vía para superar el conflicto, la solución consagrada por una de las dos normas prevalece en ciertos casos (por ejemplo, los casos en los que se verifique una propiedad adicional s) sobre la otra, mientras que en otros (por ejemplo, los casos en los que no se verifique la propiedad s) su solución resultará desplazada por la de la otra norma, esto es, reconocemos una preferencia sólo condicional de una de las normas sobre la otra, con lo que cada una conserva un cierto campo de aplicación para los casos en conflicto. En nuestro ejemplo, podríamos considerar que para los casos $p$ y $r$ en los que además se verifique la circunstancia $s$, la solución de la primera norma es la que ha de imponerse (obligatorio $q$ ), mientras que en los 
casos $p$ y $r$ en los que no se verifique $s$, la solución que ha de primar es la de la segunda norma (prohibido $q$ ). Aquí las dos normas son relevantes para determinar la solución de los casos $p$ y $r$, dependiendo de si se verifica o no $s$.

La conclusión que creo puede extraerse de este análisis es que la aceptación de una norma general para la evaluación y justificación de nuestras acciones no excluye por sí misma la posibilidad de asignar relevancia a otras circunstancias respecto de sus casos de aplicación y, por consiguiente, no parece irracional. Es más, a menos que se ofrezcan argumentos adicionales distintos de los que dan lugar a la paradoja aquí considerada, la relevancia normativa de esas otras circunstancias que eventualmente nos harían dejar de lado la solución que establece la norma general considerada no puede sino derivar de otras normas o razones generales, de ahí que este argumento no resulte suficiente para demostrar la irracionalidad en el seguimiento de normas (o razones) generales.

El problema no reside aquí en alguna arbitraria distinción verbal entre normas y razones, sino en la cuestión de su generalidad, ya que el mismo supuesto problema podría plantearse hablando exclusivamente en términos de razones normativas generales. $\mathrm{Y}$ el rechazo de la tesis que intento defender consiste en la adopción de una concepción particularista, de conformidad con la cual no existirían pautas universales en las cuales apoyar la corrección normativa de las acciones. ${ }^{18}$ Por el contrario, se debería atender siempre al modo en que, en el caso individual, se presentan las circunstancias y ponderarlas para determinar la solución correcta para dicho caso. La deliberación práctica no consistiría desde este punto de vista en la aplicación de normas generales, sino que se trataría de una práctica narrativa que permitiría apreciar la significación normativa de determinadas circunstancias para el caso concreto. ${ }^{19}$

\footnotetext{
${ }^{18}$ Cf. Dancy 1993:61 y ss.

${ }^{19}$ Cf. Moreso 2004.
} 
El particularismo parece tener un punto interesante al remarcar que no hay ningún caso particular que resulte idéntico a otro. Hare sostiene que la racionalidad en el discurso práctico está dada por la exigencia de universabilidad: si dos casos son semejantes en sus características no morales, deberían recibir idéntica solución normativa. ${ }^{20}$ Sin embargo, el particularista puede aceptar esto y, no obstante, decir que, como ningún caso particular es idéntico a otro caso particular, la exigencia de universabilidad resulta insustancial. Lo que el particularista parece sostener es que ninguna propiedad es invariablemente relevante desde el punto de vista normativo porque cualquier caso particular posee al menos una propiedad que lo distingue de cualquier otro, de manera que, como no es posible descartar que semejante propiedad resulte normativamente relevante, sería el contexto particular de un caso lo que ha de tomarse en cuenta para resolver un problema práctico.

No obstante, si bien es correcto que todo caso particular posee, al comparárselo con cualquier otro caso particular, alguna propiedad que lo distingue, esto es, que está presente en uno pero ausente en el otro, de eso no se sigue que haya al menos una propiedad que un caso particular posee y que no se encuentra en ningún otro, puesto que, cualquiera sea la propiedad que uno tome en cuenta, siempre puede existir algún otro caso particular que también la posea. Inferir de la premisa "todo caso particular posee alguna propiedad que lo distingue de cualquier otro" la conclusión "existe al menos una propiedad que todo caso particular posee y que ningún otro posee" es incorrecto, tal como lo sería inferir del enunciado "todos los chicos quieren a alguna chica" que "existe una chica a la que todos los chicos quieren". Lo primero sólo significa que para cada chico se cumple que hay alguna chica a la que quiere; lo segundo supone, infundadamente a partir de la premisa dada, que hay una chica en común a la que todos quieren. Se trata de una falacia bien conocida, que fuera denunciada por Geach como muy extendida,

${ }^{20}$ Cf. HARE 1963:10 y ss. 
¿Cómo puede el derecho obligar a quienes oprime?

en particular, en muchos argumentos filosóficos. ${ }^{21}$ En el caso del particularismo, que cada caso individual posea alguna propiedad que lo diferencia de cualquier otro resulta perfectamente compatible con la idea de que, para describir un caso particular, sólo pueden tomarse en cuenta propiedades generales. Un caso particular de homicidio, por ejemplo, siempre tendrá alguna cualidad que lo distinga de cualquier otro (en este caso particular, el homicidio se cometió con una pistola, el homicida conocía a su víctima, antes de matarlo estaban mirando juntos un partido de fútbol, etc.). Pero cada una de esas características del caso podría también verificarse en muchos otros. El único rasgo que singulariza a ese caso de homicidio es que ningún otro caso de homicidio presenta conjuntamente todas las características (generales) que se verifican en él. ${ }^{22}$ Por consiguiente, el particularismo se apoya en una premisa plausible pero deriva de ella una conclusión errónea.

\section{3. ¿Razones jurídicas autónomas?}

Luego de estos pasos previos, consideremos ahora sí la paradoja de la autoridad. En este caso, a diferencia del anterior, lo que parece que debemos afrontar no es el cargo de irracionalidad sino el cargo de irrelevancia para superar la dificultad. En efecto, desplazar el propio juicio y confiar en el de otro para cuestiones prácticas parece incuestionablemente irracional. Puede

\footnotetext{
${ }^{21}$ Cf. GEACH 1972:1-13.

${ }^{22}$ HARE sostiene que un modo simple de descartar el particularismo consistiría en sostener que no puede haber nada sobre una acción que la haga incorrecta, o sobre una persona que la convierta en mala, excepto esas características que son especificables en términos universales. Cualquier característica que no pudiera ser especificada de este modo tendría que consistir en algún tipo de esencia individual, sólo describible diciendo "esta persona" o "este acto", y permaneciendo callado a partir de entonces. Pero eso no sería describir un acto o una persona en absoluto. La única forma de describir una persona o un acto es mediante la atribución de propiedades universales (cf. HARE 1997:108). Por otra parte, en DAVIDSON 1980:105-148 se demuestra que la forma lógica de los enunciados relativos a acciones requiere siempre de cuantificadores universales.
} 
haber muchas razones por las que obedecemos a una autoridad, pero hacerlo exclusivamente porque fue ella quien emitió una prescripción no parece racionalmente justificado. Por consiguiente, el modo más plausible de lidiar con esta paradoja debería consistir en mostrar en qué casos no sería irrelevante desde el punto de vista práctico aceptar las directivas de una autoridad, esto es, en qué casos las directivas de una autoridad podrían introducir una diferencia práctica relevante. Al respecto, coincido con Bayón cuando sostiene que:

"Demostrar la relevancia práctica de la autoridad es demostrar de qué modos podría resultar falsa la tesis de la no diferencia, es decir, de qué modos sería posible que a raíz de la formulación de una prescripción por parte de una autoridad los destinatarios de la misma tuvieran una razón moral para hacer lo prescrito que no tenían con anterioridad y que no habrían llegado a tener si, ceteris paribus, aquella prescripción no hubiese sido formulada. Ciertamente las directivas de la autoridad -en tanto que hechos, consistentes en la ejecución de ciertos actos de habla en determinadas condiciones- no pueden constituir razones operativas para actuar: pero de lo que se trata es de saber cuál podría ser la estructura del razonamiento práctico que tomara en cuenta como razón auxiliar -entre otras cosas- el hecho de haberse emitido esas directivas y que tuvieran como conclusión un juicio de deber dependiente de ese hecho..." ${ }^{23}$

No examinaré aquí en profundidad la cuestión, aunque creo acertado -tal como surge de la cita transcripta- que el hecho de que una autoridad emita una directiva puede constituir en ciertos supuestos una razón auxiliar que, junto con razones operativas de carácter moral, permita justificar ciertas

\footnotetext{
${ }^{23}$ BAYÓN 1991a:604-605.
} 
acciones. Y no lo haré porque me interesa analizar el problema más específico de la autoridad del derecho o, lo que es equivalente, la cuestión de si las normas jurídicas constituyen razones para la acción y, en todo caso, en qué sentido. Adviértase que se trata aquí de justificar por qué razón las normas jurídicas obligan debido a su carácter jurídico, no por tratarse de normas o por su carácter de generales, de modo que el problema se encuentra más próximo a -si es que no se identifica con- el de la autoridad en general, no al del seguimiento de normas. Al respecto, Moreso y Vilajosana sostienen, a mi juicio acertadamente y con gran claridad, que:

“... si en el universo de las razones para actuar sólo hay espacio para las razones prudenciales y para las razones morales, ¿qué tipo de razones para la acción son las normas jurídicas? Si sólo son razones prudenciales, que funcionan en el razonamiento práctico de los agentes a través de las sanciones ajenas al incumplimiento de las normas (...), entonces siempre pueden ser desplazadas por las razones morales y, al parecer, la normatividad del Derecho queda sin explicación. Si las normas jurídicas son razones morales, entonces el Derecho es, desde el punto de vista de su relevancia práctica, superfluo, porque su normatividad es una normatividad derivada de las razones morales. Éste es, en pocas palabras, el dilema de la normatividad del Derecho. (...) [Hay], en principio, tres grandes tipos de respuesta: a) el Derecho sólo ofrece razones prudenciales para la acción, fundadas en el deseo de los seres humanos de evitar las sanciones que el Derecho coactivamente impone, b) el Derecho no ofrece por sí mismo razones para actuar de carácter autónomo, sino únicamente razones que junto con las razones morales dominantes pueden convertirse en razones derivadas, y c) el Derecho ofrece genuinas razones para la 
acción, porque en el universo de las razones para actuar no sólo hay razones prudenciales y razones morales." ${ }^{24}$

Entre las posturas que transitan esta última alternativa se cuentan el positivismo ideológico, ${ }^{25}$ la tesis de la fragmentación del discurso práctico y la concepción de las normas jurídicas como razones protegidas. No diré nada sobre la primera de ellas -esto es, la tesis de que existe un deber moral de obedecer el derecho cualquiera sea su contenido- porque me parece completamente implausible. ${ }^{26}$ En cuanto a la tesis de la fragmentación del discurso práctico, entendida como aquella que sostiene que existen tantas justificaciones como sistemas normativos sea posible diferenciar, creo que resulta irrelevante para la consideración de nuestro problema. Porque, desde luego, es posible sostener que una acción se encuentra jurídicamente justificada en razón de que existe una norma jurídica que prescribe su realización, con total independencia de la consideración que merezca tal acción desde el punto de vista de otros sistemas normativos. Pero cuando lo que está en discusión es la autoridad del derecho, la pregunta relevante es si puede considerarse que las prescripciones jurídicas configuran razones para la acción que compiten con o eventualmente desplazan a otras razones, morales, prudenciales o de la clase que sea. En consecuencia, la tesis de la fragmentación del discurso práctico no constituye un argumento destinado a

\footnotetext{
${ }^{24}$ Moreso-Vilajosana 2004:207.

${ }^{25}$ Existe una gran proximidad entre lo que se ha calificado como positivismo ideológico y lo que hoy se conoce como positivismo ético o normativista (cf., por todos, CAMPBELL 1996 y WALDRON 2001). Los partidarios de este último sostienen la tesis normativa de que el derecho debe ser identificado con independencia de consideraciones morales, y ello porque tal cosa promovería ciertos valores que se estiman deseables, ya sea morales, políticos o sociales. Sin embargo, pese a la apuntada proximidad, el positivismo ético o normativista no necesita comprometerse con la existencia de razones jurídicas autónomas.

${ }^{26}$ La postura de RosENKRANTZ se parece peligrosamente a la asunción de cierta forma de positivismo ideológico. Al menos, no encuentro un modo satisfactorio de interpretar sus dichos de modo que no colapsen en él.
} 
justificar que el derecho ofrece genuinas razones para la acción, sino que equivale a sostener que el derecho ofrece genuinas razones para la acción.

Me interesa en cambio detenerme en algunas consideraciones sobre la idea de Raz de que las normas jurídicas constituyen razones protegidas y comparar su posición con la de Frederick Schauer, porque ambos autores han desarrollado elaborados esfuerzos por dar cuenta de la autoridad del derecho sin reducirla a razones prudenciales o morales, esfuerzos que pese a sus méritos me parecen condenados al fracaso, y ello porque en ambos casos sus propuestas pretenden ofrecer una respuesta única a las paradojas de la autoridad y del seguimiento de normas. He tratado de mostrar antes en términos generales por qué los caminos para superar ambos problemas no pueden asimilarse. Intentaré hacerlo ahora en concreto examinando estas dos posiciones.

Raz señala que las normas funcionan en parte como un tipo especial de razones: como razones excluyentes.$^{27} \mathrm{~A}$ su juicio, en todo proceso de toma de decisiones, además de las razones de primer orden, pueden hallarse razones de segundo orden, que son aquellas que suministran razones para actuar o abstenerse de actuar en virtud de una razón de primer orden. Entre esas razones de segundo orden Raz considera que se cuentan aquellas que excluyen razones de primer orden, a las que llama razones excluyentes, y que obligan a dejar de lado razones que de otro modo serían aplicables. Las normas, así como las directivas de una autoridad, serían para Raz una combinación entre una razón de primer orden para llevar a cabo cierta acción y una razón excluyente que exige dejar de lado otras razones de primer orden en conflicto con la primera.

Para Raz, las razones excluyentes desplazan a aquellas razones de primer orden a las que se refieren en lugar de superarlas en peso en caso de conflicto. Entre los ejemplos que ofrece Raz se cuenta aquel según el cual una persona adopta para sí la norma de que siempre pasará sus vacaciones en Francia,

${ }^{27}$ Cf. Raz 1975:15-84 y Raz 1979:3-33. 
excluyendo la posibilidad de actuar sobre la base de una razón semejante a que los hoteles en cierta otra parte del mundo ofrecen promociones especialmente atractivas en determinada ocasión. En una situación como esa, aceptar la norma de que siempre se irá de vacaciones a Francia funcionaría para el agente como una razón de primer orden para actuar de tal modo y como una razón de segundo orden para no efectuar en cada caso un balance de las razones en juego a la hora de decidir en dónde vacacionar. Raz cree que puede justificarse satisfactoriamente que muchas veces empleemos en nuestro razonamiento práctico estrategias excluyentes de estas características $y$, en particular, que las directivas de una autoridad (y las normas jurídicas en particular) operarían de tal suerte, de manera que sería posible escapar a la segunda alternativa de la paradoja del seguimiento de normas y de la autoridad, esto es, la que destaca la irrelevancia práctica de las normas como razones o de las directivas de la autoridad.

Frederick Schauer ha cuestionado la postura de Raz planteando, respecto de un ejemplo como el comentado, qué ocurriría si el veraneante toma conocimiento de que un hotel en los Alpes austríacos ofrece habitaciones a diez dólares la noche, un precio que resulta drásticamente inferior a los cien dólares que se pensaba gastar en Francia. ${ }^{28}$ Esta oferta podría considerarse tan obviamente ventajosa que la exclusión de considerar factores semejantes podría ser derrotada, aun cuando en los casos normales (una diferencia de un veinte por ciento menos en el precio, por ejemplo) la norma no perdería su fuerza para excluir que cada año se determine dónde pasar las vacaciones sobre la base del balance completo de razones. Para Schauer, las restricciones que imponen las normas, así como las directivas de una autoridad, serían más presuntivas que excluyentes, pues suministrarían cierto grado de restricción, pero admitirían la posibilidad de que se las deje de lado en circunstancias particularmente exigentes. Al funcionar de este modo presuntivo,

${ }^{28}$ Cf. Schauer 1991:89. 
¿Cómo puede el derecho obligar a quienes oprime?

el decisor conservaría la aptitud para vislumbrar la gama completa de factores disponibles a fin de determinar si el caso analizado es uno de aquellos en los que esos factores suministran una razón de una fuerza tan excepcional como para que la razón para superar su exclusión resulte superior a la razón que suministran las normas o las directivas de la autoridad para excluirlos.

Frente a situaciones como ésta Raz, en cambio, debería optar por una de entre dos alternativas de explicación, ninguna de las cuales reflejaría la verdadera naturaleza del razonamiento práctico en casos semejantes. $\mathrm{O}$ bien debería considerar que la exclusión debe prevalecer siempre, de manera que si en la situación descripta se opta por ir a Austria, se habrá simplemente abandonado la norma; o bien debería decirse que en realidad un supuesto como el considerado no se encuentra cubierto por la norma, aunque a primera vista, debido tal vez a una interpretación poco cuidadosa de ella, haya parecido lo contrario. Para Raz, el admitir que al momento de tomar una decisión se examine incluso superficialmente la razón de primer orden para ver si ése es uno de los casos en los cuales no debería excluírsela, implicaría que la razón en cuestión no ha sido excluida en absoluto. En cambio, para Schauer esto no sería psicológicamente imposible, pues mediaría una diferencia entre un examen detenido y un simple "vistazo". Si bien Schauer reconoce que todo supuesto en el que una norma resulta derrotada puede siempre reformularse como si cayera fuera del alcance de ella, considera que una norma susceptible de ser derrotada tendría no obstante consecuencias y poseería relevancia, aunque esa relevancia se manifieste sólo en algunos casos y no en todos los comprendidos en el alcance de la exclusión.

Parecería a primera vista que la postura que asume Raz ofrece mayores reparos que la de Schauer, al menos por lo siguiente. Raz distingue entre la conformidad con una norma y el seguimiento de una norma. En el primer caso, se hace lo que la norma exige -se actúa de acuerdo con ella- cualquiera que haya sido el motivo del agente para hacerlo. En el segundo, en cambio, se hace lo que la norma exige pero, además, el agente lo hace motivado justamente por la norma -se actúa por ella-. Para Raz, las razones para 
actuar son razones para la conformidad, no para el seguimiento, y a su criterio habría ocasiones en las que la manera de hacer más probable la conformidad con un conjunto de razones radicaría precisamente en no actuar por ellas. Ese sería el modo de entender la relación entre una razón excluyente y el conjunto de razones excluidas: las razones excluyentes servirían como vías indirectas para maximizar la conformidad con las razones subyacentes que ellas excluyen. Ahora bien, de aceptar este análisis -no doy por sentado que deba aceptárselo-, las normas, así como las directivas de una autoridad, funcionarían como reglas de experiencia; no ofrecerían genuinas razones para actuar, sino más bien razones para creer: razones para creer, en situaciones de incertidumbre, que cierto curso de conducta es, con mayor probabilidad, el que se tiene razones para ejecutar. ${ }^{29}$ En otras palabras, las normas y las directivas de una autoridad no serían razones excluyentes debido a que, si se diera una genuina discrepancia entre el curso de acción que resulta impuesto por ellas y el que resulta de las razones subyacentes a ellas, habría que privilegiar al primero -en ese caso parece claro que debería optarse por el resultado del balance de las razones subyacentes-. Si las normas y las directivas de una autoridad se conciben desde este enfoque como razones excluyentes es porque, en caso de discrepancia entre el curso de acción que resulta impuesto por ellas y el que creemos que resulta de las razones subyacentes a ellas, deberíamos privilegiar al primero, y ello debido a que nuestras creencias acerca de cuál sea el resultado del balance de razones podrían resultar equivocadas.

Este análisis no me parece satisfactorio no sólo porque, como se expresó, Raz no concluye lo que en realidad sus argumentos obligan a concluir -que ni las normas generales ni las directivas de una autoridad son genuinas razones para la acción-, sino porque asimila indebidamente las normas generales con las directivas de una autoridad. No hay ninguna razón para suponer que

${ }^{29}$ Cf. BAYÓN 1991b. 
cuando hablamos de normas nos referimos exclusivamente a prescripciones de cierta autoridad. Como nuevamente apunta correctamente Bayón, cuando un agente acepta que debe realizar cierta acción p porque ello ha sido prescripto por la autoridad A, la estructura de su razonamiento práctico ha de interpretarse del siguiente modo: "1) se debe hacer lo que prescriba la autoridad A; 2) A prescribe que debe realizarse p; por consiguiente: 3 ) se debe hacer $\mathrm{p}$ ". Ahora bien, la premisa 1) en el razonamiento anterior puede expresar un deber independiente o dependiente de lo prescripto por alguna otra autoridad A'. Pero no es posible concebir una cadena infinita de razonamientos prácticos en los que la premisa mayor sea siempre la conclusión de un similar razonamiento previo, de modo que esa cadena debe romperse en algún punto aceptando un deber independiente de las prescripciones de toda autoridad, o bien debe aceptarse que no existe el deber de obedecer a ninguna autoridad. ${ }^{30}$ Por ello, aceptar que debe obedecerse a una autoridad reposa en última instancia en un juicio de deber independiente de las directivas de una autoridad $\mathrm{y}$, consiguientemente, seguir las directivas de una autoridad sólo puede justificarse apelando a otro tipo de razones. En cambio, el seguimiento de normas generales no se ve afectado por una objeción semejante. Si se acepta una norma general que establece que debe realizarse la acción p, un razonamiento como el siguiente: "1) se debe hacer lo que prescribe la norma $\mathrm{N}$; 2) la norma $\mathrm{N}$ prescribe que se debe hacer $\mathrm{p}$; por consiguiente, 3) se debe hacer p", resulta completamente prescindible porque la premisa 1) no establece ningún deber autónomo respecto de lo que expresa la conclusión 3). Por ello es que creo que las dificultades examinadas no afectan por igual a la noción de autoridad y a las normas generales.

Si ahora se examina la posición de Schauer con mayor cautela, puede apreciarse que en realidad ella conduce a una conclusión bastante semejante a la de Raz. En efecto, Schauer considera que una norma existe como tal

\footnotetext{
${ }^{30}$ Cf. BAYÓN 1991a:268-270. La precisión final no es de BAYÓN sino mía.
} 
cuando suministra una razón para la acción que es independiente de la que pueda proporcionar su justificación subyacente. Pero una razón para la acción semejante no se configura con la mera conformidad de la conducta, sino que es preciso que la norma guíe las acciones del sujeto. Ser guiado por una norma requiere que el agente tome a su existencia como una razón para la acción -no necesariamente concluyente o absoluta-. Seguir una norma, en cambio, requiere tanto ser guiado como actuar de conformidad con ella. La conformidad es entonces distinta del seguimiento porque sólo el segundo exige ser guiado por la norma. Las razones para la acción pueden o no ser absolutas. Las razones para la acción no absolutas son habitualmente consideradas razones prima facie, en el sentido de que pueden ser superadas o desplazadas por otras razones más exigentes que se inclinan en la dirección contraria. No obstante, Schauer objeta justificadamente esta calificación, pues ella parece sugerir que las razones no absolutas se evaporan cuando son desplazadas. A su criterio, tiene tanto sentido pensar que una razón no concluyente desaparece cuando resulta superada por otras razones de mayor peso como sostener que un abrigo desaparece cuando el viento lo atraviesa. Lo que ocurriría en verdad es que una norma podría ser suficiente en algunos casos y en otros no. Pero en todos ellos las normas siempre ofrecerían alguna resistencia. Para Schauer, las razones normativas constituyen un continuo: en un extremo se encontrarían las razones más débiles, ceteris paribus, que determinan resultados sólo si todo permanece igual, mientras que en el otro extremo se hallarían las razones absolutas. Como puede advertirse, Schauer discrepa aquí con Dworkin, para quien las normas siempre son concluyentes si son aplicables. ${ }^{31}$ Siguiendo a Hart, Schauer afirma que una norma sujeta a una cláusula "a menos que..." sigue siendo una norma. ${ }^{32}$

\footnotetext{
${ }^{31}$ Cf. Dworkin 1977:22-28.

${ }^{32}$ Cf. Hart 1963:174.
} 
¿Cómo puede el derecho obligar a quienes oprime?

Estas consideraciones llevan a Schauer a sostener que lo que caracteriza a las reglas de experiencia es que ellas poseen fuerza ceteris paribus, pues exigen un nivel de convicción más alto para justificar el desvío respecto del curso de acción que imponen, y presentan así algún grado de resistencia a no ser aplicadas. Las reglas de experiencia, al funcionar de este modo, se asemejarían a las normas generales. La diferencia consistiría en que las normas sólo serían vulnerables con respecto a razones externas a su justificación subyacente, mientras que las reglas de experiencia estarían sujetas a ser superadas o derrotadas frente a casos de inaplicabilidad de su propia justificación subyacente.

Según este punto de vista, las normas se caracterizarían por no resultar completamente derrotables. Pero al decir esto deberían distinguirse dos cuestiones distintas. Una norma sería internamente derrotable cuando resulta inaplicable exclusivamente sobre la base de la inaplicabilidad de sus justificaciones subyacentes. Tal sería el caso, para Schauer, de las reglas de experiencia. No obstante, una norma que posea cierta resistencia a la derrotabilidad interna -lo cual constituiría una condición necesaria para la existencia de una norma-, podría todavía resultar externamente derrotable, esto es, susceptible de ser superada por factores particularmente exigentes de carácter externo tanto respecto de la norma como de su justificación.

Cuando se examina una norma aislada, esta distinción parece meridianamente clara. Pero habitualmente las normas no se presentan en forma aislada sino conformando complejos sistemas, y frente a ellos ya no resulta fácil discernir las situaciones en las que una norma deja de resultar aplicable respecto de un caso en virtud de la inaplicabilidad de $s u$ justificación subyacente y las situaciones en las que deja de resultar aplicable en virtud de factores externos a ella o a su justificación, pero que resultan de lo dispuesto por otras normas del mismo sistema o de sus justificaciones subyacentes. Y ello porque la frontera entre lo uno y lo otro variará de acuerdo con cuál sea el criterio de identificación de las normas que se presuponga. Recuérdese que el propio Schauer admite que todo supuesto en el que una norma resulta 
derrotada puede siempre reformularse como si cayera fuera del alcance de la norma. Siendo ello así, si en un sistema conviven dos formulaciones de normas, una de las cuales dispone que "debe sancionarse a quienes cometen homicidio" y otra que establece que "no deben aplicarse sanciones a los menores de edad”, ¿qué diferencia existiría entre decir que aquí la norma que prevé una sanción para los casos de homicidio resulta externamente derrotable frente al supuesto de un homicidio cometido por un menor de edad y sostener que la norma que sanciona a los homicidas contiene implícitamente una excepción que restringe su alcance a los casos de homicidas mayores de edad?

Al considerar sistemas de normas, la distinción entre derrotabilidad interna y externa sólo conservaría sentido si los calificativos de "interno" y "externo" se refieren, no ya a las normas aisladamente consideradas, sino al sistema como un todo: en tal supuesto, una norma sería internamente derrotable si la razón para dejarla de lado surge del propio sistema, mientras que sería externamente derrotable si resulta desplazada por consideraciones extrasistemáticas, esto es, al tomar en cuenta normas pertenecientes a otro sistema al que se estima jerárquicamente superior al primero como un todo. Claro que, así entendida la distinción, ella no permite justificar que una norma aislada se interprete como una genuina norma o como una regla de experiencia. En consecuencia, y al igual que lo que ocurre en el caso de Raz, un examen detenido del modo de concebir a las normas generales en Schauer muestra que la línea de demarcación entre este tipo de normas y las reglas de experiencia es más que delgada, algo que, por otra parte, el mismo Schauer parece reconocer explícitamente al sostener que es bien poco lo que distingue a las normas que son vulnerables respecto de la inaplicabilidad de sus propias justificaciones de las que son vulnerables a ser superadas por razones externas a ellas.

Schauer sostiene que frente a un caso de aplicación, el destinatario de una norma puede creer que tiene buenas razones para estar en desacuerdo con la directiva emitida por la autoridad y, no obstante, esta última puede creer, pese a ello, que tiene buenas razones para imponerla. Hay situaciones 
en las que el incumplimiento por parte del destinatario se encuentra a su criterio justificado, cuando considerando todas las circunstancias relevantes estima que debe desobedecer la norma (por ejemplo, un niño que, frente a la disyuntiva entre obedecer la norma de ir a dormir a las nueve de la noche o ayudar a un amigo a hacer sus deberes, considera preferible desobedecer). Pero, paralelamente, la autoridad puede creer que tiene buenas razones para impedir el incumplimiento de la norma, porque a su juicio un incumplimiento en esta ocasión podría traer aparejados más perjuicios que beneficios. En una situación semejante, en la que existe un desacuerdo entre la autoridad y el destinatario de la norma, lo racional para el destinatario sería desobedecer, mientras que lo racional para la autoridad sería exigir obediencia. Se presentaría así una asimetría entre la autoridad y el destinatario, porque sería posible que frente a una determinada norma, el destinatario crea que es irracional seguirla y la autoridad crea que es racional requerir su cumplimiento. La autoridad, al momento de crear normas, puede prever la posibilidad de desacuerdos como éste y establecer sanciones -introduciendo así razones prudenciales para seguir la norma- incluso para aquellos casos en los que el destinatario crea que tiene razones para desobedecer. En especial, si predice que los casos en los que los destinatarios cometerían un error al desobedecerla superarán a los casos de obediencia injustificada. Si bien esto podría ser irracional desde el punto de vista del destinatario, resultaría perfectamente racional desde el punto de vista de la autoridad privilegiar el respeto por las normas, aunque esto implique en ocasiones llegar a resultados subóptimos. De esta manera, el carácter asimétrico de la autoridad implicaría que en ocasiones su tarea consiste en desalentar al destinatario para que utilice su mejor evaluación a través de premios y castigos y mediante una educación que inculque los valores del seguimiento de normas.

Esta salida no parece ir mucho más lejos que la solución raziana. En primer lugar, porque nuevamente se igualan aquí las directivas de una autoridad con el seguimiento de normas. Todas las consideraciones de Schauer podrían admitirse como aplicables a las primeras, pero en razón de los argumentos 
antes considerados no afectan la racionalidad en el seguimiento de normas. En segundo lugar, porque nadie cuestiona la racionalidad en el establecimiento de directivas por parte de una autoridad, sino solamente la racionalidad en su seguimiento por parte del destinatario, de modo que señalar esta asimetría entre autoridad y destinatario en lo que a la racionalidad se refiere deja todo exactamente en el mismo lugar, más allá de agregarse que, al imponer una directiva, la autoridad puede sumar razones prudenciales para su seguimiento derivadas de las sanciones correlacionadas a su trasgresión. En tercer lugar, porque si bien Schauer afirma que resultaría racional para la autoridad establecer sanciones para los casos de trasgresión a una directiva, no sólo a pesar de que el destinatario crea que sería mejor violarla, sino incluso cuando sería mejor violarla, pues de lo contrario habría escasas razones para que el destinatario obedezca cuando crea erróneamente que la violación estaría justificada, esto todavía no ofrece ningún argumento contra la objeción de la irracionalidad en el seguimiento de las directivas de una autoridad. Puede ser correcto que la autoridad esté dispuesta a sancionar a un sujeto por no seguir una de sus directivas incluso aunque, considerando todos los factores relevantes, sería mejor violarla. También puede ser correcto que desde el punto de vista de la autoridad esto resulte racional. Pero si considerando todos los factores relevantes, incluso el temor al castigo de la autoridad, es mejor violar la directiva de la autoridad que seguirla, lo que el destinatario debería hacer es violarla. Así concebidas, las directivas de una autoridad tampoco suministran verdaderas razones para la acción sino, a lo sumo, razones para creer que se debe actuar de cierto modo en situaciones de información incompleta.

Volviendo ahora a nuestro problema fundamental, esto es, el de la autoridad del derecho en situaciones de injusticia económica, y si los argumentos más elaborados que han intentado ofrecerse en apoyo de la idea de que el derecho suministra genuinas razones para la acción no parecen satisfactorios, sólo nos quedan dos alternativas. De conformidad con la primera de ellas, el derecho sólo ofrecería razones prudenciales para la acción, 
fundadas en el deseo de evitar sanciones coactivas. Desde este punto de vista, resulta trivial sostener que el derecho "obliga" a quienes trata injustamente, porque en este sentido de "obligación" -la posibilidad de emplear la fuerza para hacer cumplir sus prescripciones- el derecho no obliga incluso a quienes resultan perjudicados por las desigualdades que el derecho consagra o consiente, sino que el derecho obliga precisamente a quienes trata injustamente, pues los beneficiarios de tales iniquidades no necesitarán del refuerzo motivacional que supone la amenaza de sanciones para tener poderosas razones prudenciales para acatar las normas que protegen sus privilegios. De acuerdo con la segunda alternativa, el derecho no ofrecería más que razones auxiliares de las razones morales dominantes. Siendo ello así, las directivas que el derecho consagra podrían en ciertos casos introducir una diferencia práctica, pero sólo en la medida en que no se opongan a las razones morales que serían en sentido estricto las únicas razones operativas. Bajo esta interpretación, no parece siquiera conceptualmente posible sostener que el derecho pueda obligar cuando consagra un régimen manifiestamente injusto en el plano económico y social, pues el sentido de "obligación” aquí considerado es moral.

\section{El fundamento de la autoridad del derecho}

Los padres tienen autoridad sobre sus hijos; el maestro posee autoridad frente a sus discípulos; el sargento tiene autoridad sobre sus subordinados. Parece plausible pensar que siempre que un sujeto posee autoridad sobre otro, la posee en virtud de cierta relación que media entre ambos. ${ }^{33}$ Ahora

\footnotetext{
${ }^{33}$ RosenKRANTZ considera que cualquier explicación satisfactoria de la autoridad debe dar cuenta de dos características: su generalidad -esto es, que la afirmación de que alguien posee autoridad debe constituir una afirmación general acerca del modo en que las directivas de la autoridad deben entrar en la deliberación práctica de cualquier agente racional-, y su particularidad -en el sentido de que si x posee autoridad, la posee sólo sobre los destinatarios de sus prescripciones, con independencia de cuán justas, eficientes o correctas puedan ser.
} 
bien, si se acepta que para todo par de individuos $x$ e $y$, si $x$ se encuentra en cierta relación $R$ con $y$, entonces $x$ posee autoridad sobre $y$ (esto es, si se acepta que la satisfacción de la relación $R$ entre $x$ e $y$ es condición suficiente para sostener que $x$ posee autoridad sobre $y$ ), de ello se sigue que para todo par de individuos $x$ y $z$, si $x$ posee la misma relación con $z$, entonces posee autoridad sobre $z(\operatorname{de} \forall x, y(x \mathrm{R} y \rightarrow x \mathrm{~A} y)$ se sigue que $\forall x, z(x \mathrm{R} z \rightarrow x \mathrm{~A} z)){ }^{34}$ Por otra parte, si se acepta que para todo par de individuos $x$ e $y$, si $x$ posee autoridad sobre $y$, entonces $x$ se encuentra en cierta relación $R$ con $y$ (esto es, si se acepta que la satisfacción de la relación $R$ entre $x$ e $y$ es condición necesaria para sostener que $x$ posee autoridad sobre $y$ ), de ello se sigue que para todo par de individuos $x$ y $z$, si $x$ no se encuentra en la relación indicada con $z$, entonces no posee autoridad sobre $z$ (de $\forall x, y(x \mathrm{~A} y \rightarrow x \mathrm{R} y)$ se sigue que $\forall x, z(\sim(x \mathrm{R} z) \rightarrow \sim(x \mathrm{~A} z))) .{ }^{35}$

Para ejemplificar estos dos rasgos, RosenKRANTZ afirma que "Si ... queremos explicar la autoridad paterna debemos dar cuenta de por qué todos los hijos -y no, por ejemplo, sólo aquellos que no han madurado sus habilidades emotivas o intelectuales- deben obedecer a sus padres" y además que "Para explicar la autoridad paterna debemos explicar por qué un padre sólo puede aspirar a tener autoridad sobre sus hijos y no sobre los hijos de los demás y por qué los hijos sólo deben diferir su juicio frente a sus padres y no frente a los padres de otros". De esto puede derivarse fácilmente que, si el derecho posee autoridad, posee autoridad sobre todos sus súbditos y sólo sobre sus súbditos. Por ello, aunque ROSENKRANTZ no lo reconozca expresamente, si se acepta que una explicación satisfactoria de la autoridad del derecho ha de satisfacer estas dos exigencias de generalidad y particularidad, y si se demuestra o presupone que el derecho posee autoridad, ello alcanzaría, sin ninguna consideración adicional, para derivar la tesis central que ROSENKRANTZ intenta defender en su trabajo, esto es, que "...la injusticia económica y social no puede constituirse como una razón general para pensar que el derecho sea menos vinculante", pues el derecho obligará a todos sus súbditos con total independencia de cualquier consideración adicional. Pienso que semejante conclusión sustantiva no puede justificarse simplemente de este modo: sostener que por el mero hecho de ser súbdito de un sistema jurídico una persona le debe obediencia a sus prescripciones, con independencia de cuán justas ellas sean e incluso si la persona en cuestión es la víctima de tales injusticias, es algo que no parece fácil de justificar, y si es que puede justificarse, su justificación no puede depender exclusivamente de una estipulación conceptual.

${ }^{34}$ Este es el fundamento sobre el cual se apoya el requisito de "generalidad" de RosENKRANTZ.

${ }^{35}$ Este es el fundamento sobre el cual se apoya el requisito de "particularidad" de RosENKRANTZ. 
Así, si $a$ es padre de $b$, y la relación de paternidad es condición suficiente de la autoridad de $a$ sobre $b$, entonces si $a$ también es padre de $c$, tendrá autoridad sobre $c$. Por otra parte, si $a$ es padre de $b$, y la relación de paternidad es condición necesaria de la autoridad de $a$ sobre $b$, si $a$ no es padre de $c$, entonces no tendrá autoridad sobre $c$. A partir de esto se podría pensar que una explicación satisfactoria de la noción de autoridad debe dar cuenta de que si $x$ posee autoridad sobre la base de una cierta relación, posee autoridad sobre todos aquellos con quienes se satisface esa relación (lo cual equivale a sostener que la relación que da fundamento para sostener que $x$ tiene autoridad sobre $y$ debe constituir una condición suficiente de la autoridad de $x$ sobre $y$ ) y que, además, debe dar cuenta de que si $x$ posee autoridad sobre la base de cierta relación, no poseerá autoridad respecto de quienes no satisfagan tal relación (lo cual equivale a sostener que la relación que da fundamento para sostener que $x$ tiene autoridad sobre $y$ debe constituir una condición necesaria de la autoridad de $x$ sobre $y$ ).

Por su simplicidad, el caso de la autoridad paterna me parece muy ilustrativo para apreciar los defectos de esta posición. En contra de lo que se dijo en el párrafo anterior, parece muy sencillo demostrar que el hecho de ser padre no constituye ni una condición necesaria ni una condición suficiente para afirmar que alguien tiene autoridad sobre otra persona. Porque es fácil pensar en ejemplos en los que alguien puede tener autoridad sobre otra persona pese a no ser su padre (debido, por ejemplo, a que registra algún otro tipo de relación de superioridad en algún sentido que revista relevancia práctica) e, igualmente, que alguien puede no tener autoridad sobre otra persona pese a ser su padre (porque no lo ha reconocido como hijo, porque el hijo ya es adulto y el padre se ha tornado senil, porque se ha privado al padre de su patria potestad, etc.). Sin embargo, y pese a esto, parece muy sensato exigir a quien desee ofrecer una explicación satisfactoria de la noción de autoridad paterna que suministre un conjunto de condiciones que puedan reputarse necesarias y suficientes como para afirmar que $x$ posee autoridad sobre $y$ como padre, esto es, en razón de ser padre de $y$. ¿Cómo se congenian estas dos ideas? 
Pues bien, como se dijo, no puede aceptarse que el hecho de que $x$ sea padre de $y$ constituya una condición necesaria de la autoridad de $x$ sobre $y$. Esto parece obvio, dado que la noción de autoridad paterna es más restringida que la noción de autoridad, en el sentido de que si $x$ tiene autoridad paterna sobre $y$, entonces $x$ tiene autoridad sobre $y$, pero la conversa no vale. Consiguientemente, dar cuenta de un modo satisfactorio de la noción de autoridad paterna, si bien requiere especificar condiciones necesarias y suficientes para que alguien posea autoridad paterna sobre otra persona, no requiere asumir el presupuesto erróneo de que ser padre es condición necesaria para tener autoridad. Tampoco, como se dijo, puede asumirse sin más que el hecho de que $x$ sea padre de $y$ constituya una condición suficiente de la autoridad de $x$ sobre $y$, dado que una multiplicidad de circunstancias -quizás no ordinarias sino excepcionales- puede determinar que $x$ no tenga autoridad alguna sobre $y$ pese a ser su padre. Pero, si $x$ es padre de $y$, y no se verifican ninguna de tales circunstancias excepcionales, entonces $x$ tendrá autoridad sobre $y$. En otras palabras, si bien es cierto que una explicación satisfactoria de la noción de autoridad paterna debe especificar las condiciones necesarias y suficientes para afirmar que $x$ tiene autoridad sobre $y$ como padre, tampoco requiere asumir que el hecho de que $x$ sea padre de $y$ es condición suficiente para sostener que $x$ tiene autoridad paterna sobre $y$. Desde luego que si $x$ tiene autoridad paterna sobre $y$, de ello puede concluirse que $x$ es padre de $y$, pero $x$ podría ser padre de $y$ y no tener autoridad paterna sobre él. Una explicación satisfactoria del concepto de autoridad paterna debe asumir por definición que ser padre es condición necesaria para tener autoridad paterna, pero no obliga a asumir por definición que la relación de paternidad es condición suficiente para afirmar la existencia de autoridad paterna. Por el contrario, parece sensato pensar que ser padre sólo constituye una condición contribuyente (una condición necesaria de una condición suficiente) para tener autoridad paterna, en el sentido de que si $x$ es padre de $y$, y no se dan ciertas circunstancias excepcionales, entonces podremos afirmar que $x$ tiene autoridad paterna sobre $y$. 
¿Cómo puede el derecho obligar a quienes oprime?

En síntesis, parece que un principio de explicación de la noción de autoridad paterna podría esquematizarse del siguiente modo:

(1) Si $x$ tiene autoridad paterna sobre $y$, entonces $x$ es padre de $y$.

(2) Si $x$ es padre de $y$, y no se verifican ciertas circunstancias excepcionales c...c , $x$ tiene autoridad paterna sobre $y$.

A lo que habría que agregar:

(3) Si $x$ tiene autoridad paterna sobre $y$, entonces $x$ tiene autoridad sobre $y$.

Por supuesto, la conversa de (3) no vale. ${ }^{36}$

No obstante lo que se dijo sobre lo aleccionador que podría resultar un examen de la autoridad paterna para apreciar las deficiencias del argumento considerado, pensar que un análisis de la autoridad jurídica pueda reconstruirse de una manera análoga a la noción de autoridad paterna me parece desafortunado. Porque en el caso de la autoridad paterna resulta muy claro que existe una relación, la relación padre-hijo, que reviste relevancia fundamental. En cambio, no es claro que esto mismo pueda sostenerse en el caso de la autoridad del derecho. Ser súbdito de un sistema jurídico no parece tener en el caso de la autoridad jurídica el mismo papel que posee la relación padre-hijo en el caso de la autoridad paterna. Porque ser súbdito de un sistema jurídico o bien significa simplemente estar obligado por el derecho, con lo que no puede tener ningún papel explicativo de la idea de autoridad jurídica, o bien ha de entenderse en el sentido de ser destinatario de las prescripciones jurídicas, esto es, que el derecho pretende obligarlo, ${ }^{37}$ pero en

\footnotetext{
${ }^{36}$ De conformidad con este análisis, la noción de autoridad paterna satisface la condición de particularidad pero no la de generalidad.

${ }^{37}$ En este último caso, una dificultad adicional estriba en que si bien las normas de un cierto sistema jurídico son generales en cuanto a las circunstancias y, con pocas excepciones, generales en cuanto a los sujetos destinatarios, esto último no significa necesariamente que los destinatarios de las normas jurídicas sean siempre un mismo conjunto de personas. Por el contrario, la mayoría de las normas de un sistema jurídico posee diferentes clases de destinatarios. No obstante, incluso despreciando esta dificultad y considerando de un modo harto simplificado que, por ejemplo, las normas jurídicas argentinas tienen por destinatarios a los argentinos, tal afirmación así formulada parece claramente falsa desde el momento en que las normas jurídicas argentinas se aplican en un sinnúmero de casos a no argentinos.
} 
este sentido parece claro que la relación de ser súbdito de un sistema jurídico es irrelevante para nuestro problema. La pregunta acerca de la autoridad del derecho consiste en intentar dilucidar si el derecho obliga, en tanto tal, a quienes pretende obligar y, en todo caso, por qué. En otras palabras, nuestra pregunta es, justamente, si y por qué las normas de un sistema jurídico obligan a quienes pretenden obligar.

Fuera de la indicada relación, no se aprecia a primera vista qué otra relación podría tener el mismo papel capital a la hora de explicar la noción de autoridad jurídica. No obstante, supongamos por hipótesis que existe una relación semejante: voy a denominarla pertenencia a una misma comunidad politica, sin mayores precisiones por ahora. ${ }^{38} \mathrm{Si}$ tal fuera el caso, entonces sí podríamos proyectar el análisis efectuado sobre la autoridad paterna para la evaluación de la autoridad jurídica. Si la analogía se mantiene, que $x$ pertenezca a la comunidad política $\mathrm{CP}$ no puede constituir una condición necesaria para considerar que las normas del sistema jurídico de $\mathrm{CP}$ poseen autoridad sobre $x$, porque las normas del sistema en cuestión podrían obligarlo por otras razones, esto es, pese a no ser miembro de CP. Tampoco podría constituir una condición suficiente para considerar que el sistema posee autoridad sobre $x$, porque podría ocurrir que $x$ sea miembro de la comunidad política CP y, no obstante, $x$ tenga muy buenas razones para desobedecer sus prescripciones. Pero podría admitirse que el hecho de que el sistema tenga autoridad jurídica sobre $x$ es condición suficiente para sostener que tiene autoridad sobre $x$; que si el sistema de CP tiene autoridad jurídica sobre $x$, entonces $x$ es miembro de la comunidad política CP y que si $x$ es miembro de la comunidad política $\mathrm{CP}$, entonces, si no se verifican ciertas circunstancias excepcionales, el sistema de CP tendrá autoridad jurídica sobre $x$ (esto es, que $x$ sea miembro de CP sería una condición contribuyente para que el sistema tenga autoridad jurídica sobre $x$ ).

${ }^{38}$ Esa es la relación que examina RosENKRANTZ en su trabajo. 
En conclusión, asumiendo por hipótesis que la autoridad del derecho se apoya en una cierta relación relevante, como la pertenencia a una misma comunidad política, una explicación satisfactoria de la autoridad del derecho como derecho, debería dar cuenta de que la satisfacción de tal relación es condición necesaria de la autoridad jurídica sobre quienes la satisfacen, esto es, que si alguien no es miembro de la comunidad política en cuestión, el sistema correspondiente a dicha comunidad política no tendrá autoridad jurídica sobre él, pero no exige suponer que sea, además, condición suficiente de tal autoridad, esto es, que para todo miembro de la comunidad política el sistema jurídico correspondiente posea autoridad jurídica sobre él.

(1) Si el derecho de CP tiene autoridad jurídica sobre $\mathrm{x}$, entonces $x$ es miembro de CP.

(2) Si $x$ es miembro de CP, y no se verifican ciertas circunstancias excepcionales c ...c , entonces el derecho de CP tiene autoridad jurídica sobre $x$.

${ }^{\mathrm{n}}$ A lo que cabría agregar:

(3) Si el derecho de CP tiene autoridad jurídica sobre $x$, entonces el derecho de CP tiene autoridad sobre $x$.

Por supuesto, la conversa de (3) no vale. ${ }^{39}$

Ahora bien, para que la analogía se mantenga, la relación de membresía a una misma comunidad política debería satisfacer un requisito que satisface la relación padre-hijo. Cuando se dice que $x$ tiene autoridad paterna sobre $y$, lo que se sostiene es que $x$ tiene autoridad sobre $y$ por ser su padre y no por otra razón, en el sentido de que el hecho de que $x$ sea padre de $y$ es una condición-en las condiciones antes especificadas-que resulta normativamente relevante para considerar que sus prescripciones obligan a $y$.

\footnotetext{
${ }^{39}$ De conformidad con este análisis, la noción de autoridad jurídica, al igual que la autoridad paterna, satisfaría la condición de particularidad pero no la de generalidad.
} 
Pero a diferencia de la relación padre-hijo, la relación de membresía a una misma comunidad política no constituye un hecho normativamente relevante que permita justificar la autoridad del derecho. La noción de "comunidad política" no puede sino ser una construcción teórica, de modo que la exigencia de pertenencia a una misma comunidad política carece de todo significado por sí misma. Cualesquiera que sean las condiciones que se exijan para considerar que alguien forma parte de una misma comunidad política con otros, será la satisfacción de tales condiciones, y no la relación de pertenencia a la construcción teórica "comunidad política", lo que determine en qué casos y sobre quiénes se estima que posee autoridad el derecho. ${ }^{40}$

${ }^{40}$ Rosenkrantz afirma que su “...concepción de la membresía ... es la siguiente: carezco del vínculo adecuado con mi comunidad, y por lo tanto sus decisiones no pueden ser vinculantes (por lo menos en lo que a mi respecta), cuando a) el funcionamiento de las instituciones de mi comunidad impide que, como cuestión de hecho, tanto mis opiniones como mis intereses cuenten en el proceso de toma de decisión colectiva, o cuando b) las instituciones están organizadas precisamente a los efectos de que o mis opiniones o mis intereses no cuenten en dicho proceso." Al respecto me parece, en primer lugar, que la segunda de tales exigencias resulta completamente superflua: si de hecho ni mis opiniones ni mis intereses cuentan, la razón por la cual no cuentan -porque las instituciones están organizadas para que no cuenten o por cualquier otra razón- resulta irrelevante. En el único caso en que tendría sentido conservar la alternativa b) junto a la alternativa a) sería cuando las instituciones están organizadas con el objeto de impedir que mis opiniones o intereses cuenten pero que ese objetivo no se logre, de modo que pese a ello mis opiniones e intereses sí cuenten. No obstante, en ese caso me parece obvio que cualquiera que asuma este punto de vista concluiría que soy miembro de la comunidad política. En segundo lugar, resulta difícil entender en qué consiste concretamente la pauta de RoSENKRANTz de que los intereses de todos los miembros de una misma comunidad política cuenten en el proceso de toma de decisiones. Porque, por una parte, no todos los intereses de cualquiera merecen contar: mi interés en que no se mude frente a mi casa una familia negra -ya sea por simple discriminación o porque temo que la discriminación de otros deprecie el valor de mi casa- no merece ser tomado en cuenta. Y porque, por otra parte, lo relevante de tomar en cuenta los intereses de todos es que parece injustificable tomar en cuenta los intereses de $x$ y en cambio no tomar en cuenta los intereses de $y$, sólo porque son sus intereses. En otras palabras, la razón por la cual han de tomarse en cuenta los intereses de todos es porque sólo así se los trata como iguales. De manera que si es la igualdad lo que exige tomar en cuenta los intereses de todos, resulta incongruente concluir que esta pauta es compatible con las mayores desigualdades económicas. 
¿Cómo puede el derecho obligar a quienes oprime?

\section{Ilegitimidad de las desigualdades}

Para concluir mi trabajo efectuaré algunas consideraciones sobre el interrogante del último párrafo del punto anterior, esto es, en qué casos y sobre quiénes puede sostenerse que el derecho posee autoridad, en el sentido que he intentado precisar hasta aquí. Más específicamente, quisiera tratar de aclarar por qué no creo que pueda decirse que el derecho impone genuinos deberes en contextos de manifiesta desigualdad económica.

De acuerdo con un reciente estudio de la CEPAL, en América Latina y el Caribe, sobre un total de unos 512 millones de personas, 222 millones viven en la pobreza y 96 millones (un 18,6 por ciento de la población) en la indigencia, esto es, condenados a subsistir con menos de un dólar por día. ${ }^{41}$ La pobreza extrema nos conmueve y nos resulta intolerable: es casi inhumano permanecer impasible frente a familias enteras que viven buscando en los basurales algo para comer o frente a chicos que mueren por desnutrición. Permítaseme ofrecer un ejemplo, para que se entienda de qué estoy hablando:

"Desafiando temperaturas bajo cero, un padre trasladó a su hija, que padece un grave cuadro de desnutrición, durante 10 horas por cerros y valles catamarqueños para que fuera asistida por un médico. Avelino Vega, que tiene 12 hijos, tomó la decisión luego de que el lunes su nena sufrió una fuerte descompensación, debido a la desnutrición que padece. "Mi hija tiene una salud muy frágil. El lunes tuvo una fuerte descompensación e interpreté que se estaba muriendo, por lo que decidí salir de Río Grande caminando con mi hija en brazos, con mucho abrigo", relató. El hombre, que no tiene trabajo ni ingresos fijos, explicó que luego de caminar durante

\footnotetext{
${ }^{41}$ Diario Clarín de Argentina, edición del 11 de junio de 2005 (http://www.clarin.com/diario/ 2005/06/11/elmundo/i-04002.htm).
} 
10 horas, llegó a la localidad de Tatón el martes a las 8 y lo trasladaron en vehículo hasta Fiambalá donde fue atendida su hija." 42

No obstante, en una sociedad en la que todos fuésemos igualmente pobres en el sentido de no ver cubiertas nuestras necesidades básicas, ${ }^{43}$ aunque seguramente tendríamos poderosas razones para sentirnos insatisfechos, habría muy poco que reprochar en cuanto a su justicia. Porque la pobreza no es un problema moral: el problema es la desigualdad. Y los sistemas jurídicos no son agentes inocentes respecto de este problema, puesto que me parece incuestionable, tal como lo sostiene Dworkin, que:
“...la distribución de la riqueza es el producto de un orden jurídico: la riqueza de una persona depende decisivamente de qué leyes ha promulgado su comunidad -no sólo las leyes que gobiernan la propiedad, los delitos contra ella, los contratos, la responsabilidad por daños, sino las leyes de

\footnotetext{
${ }^{42}$ Diario Clarín de Argentina, edición del 20 de julio de 2005 (http://www.clarin.com/diario/ 2005/07/20/um/m-1017673.htm). Imagínese que el Sr. Vega en medio de su recorrido encuentra un vehículo ajeno y se lo roba para llevar a su hija a un hospital. O mejor, que luego de lo acontecido decide comenzar a cortar rutas reclamando de las autoridades políticas que se adopten los recaudos necesarios para que nadie en el futuro tenga que vivir lo que él vivió. ROSENKRANTZ reconoce que "El derecho no puede reclamar conductas heroicas y sería heroico exigir de alguien que no se defienda o que se abstenga de perjudicar bienes de otros cuando algo suyo de mayor importancia está en peligro". No obstante, le parece difícil que eso ocurra en el caso de las desigualdades económicas, pues las víctimas de tales injusticias desobedecerían el derecho “...con el objeto no de preservar un bien propio sino de, simplemente, llamar la atención sobre su propia situación, ejerciendo presión o violando los derechos de personas distintas a aquellas que son las estrictamente responsables de la situación en la que ellas se encuentran". No tengo nada para agregar a esto.

${ }^{43}$ La pobreza puede ser entendida de dos maneras distintas: como una relación comparativa y relativa, o como un atributo con carácter absoluto. En el primer sentido, se dirá que $x$ es más/ menos pobre que $y$ si y sólo si $x$ tiene menos/más recursos que $y$. En el segundo sentido, se dirá que $x$ es pobre (simpliciter) si y sólo si posee recursos inferiores a cierto umbral.
} 
¿Cómo puede el derecho obligar a quienes oprime?

asistencia social, las impositivas, las laborales, las que confieren derechos civiles, las regulaciones del medioambiente y las leyes que reglamentan prácticamente cualquier otra cosa." 44

Por supuesto, puede ser que ciertas desigualdades de trato posean justificación, pero esto presupone exactamente lo que quiero resaltar: que las desigualdades requieren de una justificación..${ }^{45}$ Con todo, aún aceptando esto, se podría pensar que el ideal abstracto de tratar a las personas como iguales, de brindar igual consideración a los intereses de todos, es compatible todavía con numerosas concepciones diferentes de la igualdad. Tomar en cuenta el punto de vista de cada uno y tratarlo como si fuera tan importante como el nuestro sería compatible con hacer que la satisfacción de preferencias entre todos alcance su máximo grado, con asegurar a cada uno un cierto nivel mínimo de recursos y libertades, con hacer lo que es mejor para los que están situados en la peor posición, entre otras posibilidades. ${ }^{46}$ La aceptación del ideal abstracto de la igualdad no nos dice todavía cuál de estas u otras concepciones de la igualdad es la más satisfactoria.

${ }^{44}$ DwORKIn 2000:1. La traducción es mía.

${ }^{45}$ Con respecto a la pregunta acerca de si las víctimas de la injusticia económica y social están obligadas a obedecer el derecho RosENKRANTZ no ofrece ningún argumento general en apoyo de su respuesta afirmativa, sino sólo algunas consideraciones sobre la situación en Argentina. Doy por sentado que su respuesta es afirmativa porque si bien en alguna parte de su paper parece tener reparos en reconocerlo expresamente, e incluso afirma "...yo no pretendo ofrecer una respuesta concluyente al problema de la relación entre la injusticia y el derecho en las particulares circunstancias argentinas ni ninguna otra conclusión práctica”, en la conclusión expresa que "Si lo que he dicho es correcto, la injusticia económica y social no puede constituirse como una razón general para pensar que el derecho sea menos vinculante”. Con relación a Argentina, RosENKRANTZ estima que hay un sistema "relativamente eficaz en la reproducción de las opiniones de los que menos tienen”, y ello debido fundamentalmente a que el voto es obligatorio y a que "los partidos politicos mayoritarios declaran representar los intereses de los postergados". Esto me parece un argumento minúsculo como para concluir que los pobres no pueden ser considerados alienados en nuestra sociedad y, consiguientemente, que el derecho tal como es posee autoridad sobre ellos.

${ }^{46}$ Cf. Mackie 1984:92; KyMLICKA 1990:54. 
No tengo problemas en aceptar que se discuta en estos términos, siempre y cuando no nos dejemos engañar por la carga emotiva favorable que parece conferirle esta presunta aceptación de un ideal de igualdad vaciado de todo contenido sustantivo a posturas que sólo buscan legitimar ciertas formas de desigualdad. Hecha esta salvedad, me gustaría tratar de mostrar a través de la consideración de unos pocos argumentos bien conocidos, que incluso los esfuerzos teóricos más significativos llevados a cabo para intentar justificar desigualdades en el plano económico parecen insatisfactorios.

Un buen comienzo es examinar brevemente el liberalismo conservador de Nozick. ${ }^{47}$ A juicio de Nozick, si se parte de una distribución D que se reputa justa, incluso aunque ella sea igualitaria, debería admitirse que mediante transacciones libremente consentidas se puede llegar a una distribución D’ no igualitaria, que debería también ser considerada justa, puesto que la situación de origen es justa y el procedimiento de variación no parece tener nada de objetable dado que se trata de transacciones voluntarias entre adultos. Para ello emplea el conocido ejemplo de Wilt Chamberlain. Ahora bien, si usted vive en una sociedad perfectamente igualitaria, ¿aceptaría pagar un sobreprecio de 25 centavos en su entrada a un partido de basquet para ver jugar a Wilt Chamberlain, siendo que ese sobreprecio será exclusivamente para el jugador, de modo tal que Chamberlain se volverá mucho más rico que los demás, y esto implicará, entre otras cosas, que los hijos de Chamberlain, aunque no hagan ni siquiera la estúpida contribución que hace Chamberlain a la sociedad, vivirán una vida incomparablemente mejor que la de sus propios hijos? El argumento resulta insostenible pues presupone lo que pretende demostrar: ${ }^{48}$ si la distribución D se reputaba justa, lo era porque era igualitaria; si un procedimiento conduce de tal distribución a otra distribución D’ no igualitaria, resulta injusto. Usted puede consentir desprenderse de parte de su dinero

\footnotetext{
${ }^{47}$ Cf. NozICK 1974.

${ }^{48}$ Cf. Nagel 1995; Gargarella 1999:57, KyMlicka 1990:116-118.
} 
para ver jugar a Chamberlain mientras el único perjudicado sea usted, pero esa acción sólo puede admitirse con el límite de que no perjudique a terceros. Y los terceros se perjudican no sólo cuando se los priva de algo que poseen, sino también cuando se altera lo que poseen los demás o el modo en que se distribuye lo que poseen los demás. ${ }^{49}$ ¿Por qué tendría yo que aceptar que a partir de sus acciones los hijos de Chamberlain vivan mejor que los míos? Despréndase usted de sus 25 centavos, pero eso no le da a Chamberlain ningún derecho de propiedad plena sobre ellos.

Pero además de lo señalado, las transacciones entre adultos sólo pueden operar sobre algo que se posee legítimamente, de ahí que Nozick necesite justificar cuándo puede considerarse justo que alguien se apropie de recursos externos. La alternativa a primera vista más plausible es que se califique como justa aquella apropiación que deje abierta para los demás la posibilidad de apropiarse de otros recursos en la misma cantidad y calidad. No obstante, Nozick sostiene que esta exigencia es excesiva, y trata de demostrarlo con un argumento que, en caso de que se efectuara un ranking de los diez peores argumentos utilizados en la historia de la filosofía, sin lugar a dudas debería ocupar un sitio en la lista. La idea es la siguiente: si la gente se apropia de recursos de modo tal que cuando llegamos a una cierta persona, digamos $z$, ésta se queda sin nada, habría que considerar que la apropiación del anterior, digamos $y$, fue injusta porque no dejó abierta la posibilidad de que $z$ se apropiara de recursos en la misma cantidad y calidad que él. Pero entonces también sería injusta la apropiación que hizo el anterior, digamos $x y$, siguiendo idéntico razonamiento, ninguna de las apropiaciones podría calificarse como justa. Concluye de esto Nozick que, siendo esta exigencia demasiado fuerte, deben considerarse justas aquellas apropiaciones que no dañen a otros, resultando esto compatible a su criterio con que unos pocos

${ }^{49}$ Cf. Cohen 1977:218. 
acaparen recursos de manera desigual respecto de la enorme mayoría. ${ }^{50}$

Para simplificar el análisis del argumento de Nozick, consideremos únicamente la apropiación de la tierra, y supongamos como hipótesis que sólo existen 100 hectáreas de tierra, toda ella de exactamente la misma calidad, y que de momento hay sólo 10 personas en el mundo. ${ }^{51}$ ¿En qué caso diríamos que la apropiación de la tierra hecha por alguien es justa? La respuesta obvia es que lo justo sería que cada uno se apropie únicamente de 10 hectáreas, lo que equivale a decir que es justa una apropiación de tierra en la medida en que deja abierta para los demás la posibilidad de apropiarse de exactamente la misma cantidad de tierra. Hasta aquí, el argumento de Nozick no tiene cabida alguna: en la medida en que se mantengan constantes tanto los recursos como las personas, la pauta de dejar la posibilidad a otros de apropiarse de la misma cantidad de recursos siempre es aplicable y depende exclusivamente de una operación de división, de manera que la situación planteada por Nozick del pobre $z$ que se queda sin nada no se verifica. Si se verificara, ello por

${ }^{50}$ El razonamiento de NozicK recuerda una falacia lógica que fuera denunciada en el marco de los estudios efectuados en los años ' 50 de una familia de paradojas denominadas "paradojas pragmáticas". Un ejemplo de este tipo de paradojas es el del examen sorpresa. El profesor anuncia al comienzo del curso que antes de su finalización tomará un examen sorpresa, esto es, sin previo aviso y sin que nadie pueda determinar por anticipado cuándo va a acontecer. El alumno Nozick convence a sus compañeros de que tal examen no se tomará nunca con el siguiente argumento: "un examen como el propuesto no podría tomarse el último día del curso, porque si se dejaran pasar todos los días de clase salvo el último sin tomar el examen sorpresa, podríamos predecir sin dificultad que se tomará ese último día, pero entonces el examen no tendrá nada de sorpresivo. Ahora, siendo ello así, tampoco puede tomarse este examen el penúltimo día de clase, porque entonces, sabiendo que no puede ser tomado el último día, y si sólo quedan dos días de clase, entonces podremos predecir con facilidad que el examen se tomará ese día. Argumentos similares obligan a descartar todos los días de clase, de modo que no puede haber examen sorpresa". Al día siguiente el profesor toma el examen sorpresa y todos los alumnos resultan reprobados, empezando por NozicK, a quien además sus compañeros le propinan una golpiza.

${ }^{51}$ Suprimir el problema de la calidad es por supuesto artificial, pero no soy yo el que está tratando de probar que es justo que la gente se apropie de algo sino NozicK. 
cierto no demostraría que no se puede efectuar una distribución que deje a los demás igual cantidad de recursos, sino solamente que no se lo ha hecho.

Desde luego, la situación hipotética planteada no puede ser la que tiene en mente Nozick. Lo que parece presuponer su argumento es que la pauta considerada, si bien puede funcionar en el plano estático, digamos en un tiempo $t$, no puede funcionar en el plano dinámico, si es que varían ya sea la cantidad de recursos o el número de personas. En el tiempo $t$ cada uno de los 10 habitantes del mundo nos apropiamos justamente de 10 hectáreas de tierra, pues dejamos abierta para los demás la posibilidad de apropiarse de la misma cantidad de tierra si es que desean hacer lo mismo. Pero ahora resulta que en $t$ uno de los diez pobladores tiene un hijo, a quien no le hemos dejado nada para apropiarse. Consiguientemente, lo que era un conjunto de apropiaciones justas pasa a ser un conjunto de apropiaciones injustas a la luz de nuestro criterio. Todo esto es correcto; ahora bien, ¿cuál es la conclusión de Nozick? Que tenemos que debilitar nuestro criterio de apropiación justa porque el empleado no puede ser satisfecho. Pero esto es un error: lo único que demuestra el argumento de Nozick es que este criterio de apropiación justa no consiente el otorgamiento de derechos irrevocables. Si cambian las circunstancias, será preciso volver a aplicar el mismo criterio. En nuestro ejemplo, si ahora somos 11 habitantes, las 100 hectáreas deberían ser igualitariamente distribuidas a razón de 9,09 hectáreas para cada uno.

A esto podría objetársele que la idea de apropiación ya presupone el otorgamiento de derechos irrevocables, que esto es justamente lo que se está buscando justificar, por lo que nuestra pauta de dejar subsistente la posibilidad de que los demás se apropien de igual cantidad y calidad de recursos no resultaría una pauta adecuada de "apropiación" justa. De hecho, Nozick habla de derechos "permanentes y hereditarios". No obstante, cualquiera sea el criterio de apropiación justa que se emplee, cuando varíen las circunstancias se requerirá igualmente reevaluar las apropiaciones para determinar si se siguen ajustando a la pauta escogida $\mathrm{y}$, eventualmente, efectuar las rectificaciones que correspondan. El mismo Nozick reconoce esto: si cada 
uno de nosotros posee un pozo de agua, pero un desastre natural hace que todos menos el mío se sequen, esta circunstancia obliga a reconocer un límite a mi derecho de propiedad. Por consiguiente, como cualquier criterio de apropiación justa obliga a ajustes y rectificaciones si varían las condiciones iniciales, y como si no se aceptan reajustes en función de cambios en las circunstancias ningún criterio puede justificar apropiaciones que confieran derechos irrevocables, el argumento de Nozick resulta inadmisible también en el plano dinámico. ${ }^{52}$

Otra posible justificación de la desigualdad que ha sido extensamente analizada es la que puede construirse sobre la base de la idea utilitarista de la promoción del mayor bienestar general: las desigualdades económicas podrían justificarse en los casos en los que ellas maximicen la suma o la media (según las diferentes corrientes utilitaristas) de bienestar general, esto es, si producen el bienestar agregado más elevado. El utilitarismo se apoya en la idea fuertemente intuitiva de que un examen de la corrección moral de una acción no puede desentenderse de sus consecuencias sobre las personas. Por otra parte, el cálculo utilitarista cuenta como iguales las preferencias de todos, concretando de esa forma el ideal de igual consideración.

Sin embargo, y como primera dificultad, el utilitarismo no toma en cuenta quiénes resultan ser los titulares de las preferencias que se satisfacen o se sacrifican. En el plano individual, una persona puede sacrificar algunas

\footnotetext{
${ }^{52}$ NozICK, si bien "consciente de la dificultad de rehuir un pasado intelectual”, ha expresado posteriormente su "insatisfacción” con la perspectiva defendida en Anarquía, estado y utopía. De todos modos, para este "nuevo" (?) NozICK, las políticas públicas tendientes a corregir las atroces desigualdades que se registran en nuestras sociedades sólo se justificarían porque "expresan simbólicamente nuestros lazos de afecto", porque son "expresión pública conjunta de afecto y solidaridad". Y aunque "esta afirmación pública conjunta no es simplemente verbal; aquellos en nombre de quienes se habla quizá deban pagar impuestos para ayudar a soportar los programas que ello implica", Nozick estima que "alguien que objeta por razones morales las metas de una política pública debería contar con permiso de la sociedad para no ser incluido en dicha política" (NozIcK 1989:228-230). Un "arrepentimiento" semejante se parece mucho a una hipocresía.
} 
de sus preferencias con el objeto de maximizar la satisfacción de otras. Pero el utilitarismo traslada esta misma operación al plano colectivo, de lo que resulta que las preferencias de ciertas personas pueden verse sacrificadas en beneficio de la satisfacción de las preferencias de otras personas, lo cual implica no respetar a los individuos como seres autónomos. En segundo lugar, el que se persiga maximizar el bienestar provoca una dificultad ligada a este último concepto: computar como iguales las preferencias de todos obligaría en principio, siendo que cada fuente de utilidad tiene igual importancia, a tomar en cuenta preferencias caras -mi gusto por desayunar todas las mañanas champagne francés y caviar ruso debe contar igual que su gusto por desayunar mate cocido con bizcochos de grasa-, lo cual parece contraintuitivo debido a que cada quien debería responsabilizarse por sus elecciones y no deberíamos esperar que nos subvencionen nuestras preferencias caras. Claro que no resulta muy sencillo efectuar un corte aquí tomando en cuenta la idea de responsabilidad, porque también se presenta el problema de las preferencias poco ambiciosas que son producto de una falsa conciencia -su gusto por el mate cocido y los bizcochos puede obedecer a que, como estrategia de supervivencia, usted se ha convencido de que no merece un desayuno más suculento-. Y eso no es más que el comienzo: una persona no sólo tiene preferencias respecto de los bienes, recursos y oportunidades que han de corresponderle a ella sino también preferencias respecto de los bienes, recursos y oportunidades que a su criterio deberían corresponderle a los otros. ${ }^{53}$ Siendo así, tendremos que incorporar en el cálculo de utilidad la preferencia discriminatoria del vecino que no quiere que se mude a su barrio una familia negra, porque son negros, tanto como mi preferencia de que no se mude a mi barrio una familia negra porque, si bien no tengo ningún problema con los

53 DwORKIN llama a las primeras preferencias personales y a las segundas preferencias externas (cf. Dworkin 1977:234). En DwORKIN 2000:17, en cambio, se traza una distinción diferente entre preferencias políticas, impersonales y personales. 
negros, preferencias como la de mi vecino harán que mi casa pierda valor. Aquí se genera un grave dilema para el utilitarismo: porque o bien se computan todas estas execrables preferencias en el cálculo de utilidad para determinar el valor moral de las acciones, lo cual parece completamente inaceptable, o bien se las excluye sobre la base de algún iluminado criterio de selección de "preferencias informadas", en cuyo caso se pierde el atractivo básico del utilitarismo de tomar en consideración las preferencias de la gente de carne y hueso en un pie de igualdad, y todo el cálculo se convierte en una ficción acerca de lo que preferirían ciertos seres plenamente racionales. Y la salida a este dilema consistente en bloquear preferencias de este tipo mediante el reconocimiento de un conjunto mínimo de derechos para toda persona no se encuentra disponible para el utilitarista porque en esta concepción nada corresponde a alguien por derecho con carácter previo al cálculo de utilidad. ${ }^{54}$

Obviaré otras diversas objeciones que se han dirigido contra el utilitarismo. Sólo desearía agregar que tomar al principio de utilidad como pauta de corrección moral enfrenta al utilitarismo con otro dilema, tanto o más serio que el anterior y más directamente vinculado con el problema de las desigualdades. Como lo puntualiza correctamente Kymlicka, existen centralmente dos argumentos con los que puede justificarse el incremento de la utilidad como criterio de corrección moral: por una parte, el utilitarismo puede intentar justificarse sosteniendo, como se dijo, que trata a las personas como iguales, con igual consideración y respeto, al asignar el mismo peso a las preferencias de cada uno, sin importar el contenido de tales preferencias;

\footnotetext{
${ }^{54}$ Algunos de los problemas comentados han intentado sortearse mediante la sustitución del utilitarismo de actos, es decir, el que postula la aplicación directa del principio de utilidad para la evaluación de la corrección moral de los actos, por el utilitarismo de reglas, esto es, aquel que sostiene que el test de utilidad se aplica para determinar qué reglas deben seguirse, y luego las acciones se evalúan en función de tales reglas. No obstante, David Lyons ha controvertido seriamente esta propuesta con el argumento de que ambas formas de utilitarismo resultarían en realidad equivalentes (cf. LYONS 1965:capítulo 4), un argumento que tiene fuerte vinculación con las paradojas de la autoridad y del seguimiento de normas generales comentadas en el punto 2 .
} 
por la otra, el utilitarismo puede justificarse teleológicamente porque promueve la obtención de un estado de cosas que se reputa valioso, y si se cuenta a los individuos como iguales es simplemente porque éste es el modo de alcanzar dicho estado de cosas. Ahora bien, si la versión adecuada del utilitarismo es la reflejada en este segundo argumento, entonces las personas sólo cuentan como medios y se pierde el atractivo originario que parecía presentar esta doctrina al evaluar la corrección moral de las acciones en función del bienestar de los seres humanos -pues el énfasis se pone aquí en el bienestar, no en los seres humanos-. Pero si en cambio se estima que la versión correcta del utilitarismo es la primera, entonces no hay modo de justificar un compromiso autónomo con la maximización del bienestar y sólo debería empleárselo cuando represente la forma más adecuada de tratar a las personas como iguales. ${ }^{55}$

Lo que el dilema pone de manifiesto es que no se puede sostener coherentemente que la moral tiene que ver con el incremento del bienestar y con la igual consideración de todos los individuos, esto es, que el utilitarismo asume una concepción inadecuada de la igualdad. Si el interés esencial de las personas es la satisfacción de preferencias, y que se otorgue a cada uno igual consideración, ¿qué otra cosa se puede hacer más que darle la misma importancia a las preferencias de cada uno? No obstante, si maximizar la utilidad se preocupa por tratar a las personas como iguales, ello choca con nuestras intuiciones de lo que significa igual consideración, pues se trata a las personas como medios para los fines de otros. Al menos parte de lo que significa mostrar igual consideración y respeto hacia otros es tener en cuenta lo que les corresponde por derecho, de manera que el utilitarismo no puede garantizar que las personas sean tratadas como iguales ya que carece de una teoría de los derechos.

La idea rawlsiana de que las desigualdades económicas y sociales deben estructurarse de tal manera que redunden en un mayor beneficio de los peor

${ }^{55}$ Cf. KyMlicka 1990:45 y ss. 
situados parece mucho más promisoria que los caminos anteriores. ${ }^{56}$ Rawls ofrece su teoría como un modo de superar el ideal de la igualdad de oportunidades. En una sociedad en la que rigiese el principio de igualdad de oportunidades, el éxito o fracaso estaría determinado por el rendimiento, las elecciones y el esfuerzo, no por circunstancias sociales por las que la gente no tiene responsabilidad. Pero si bien Rawls reconoce el atractivo de esta idea básica, considera que existe otra fuente de desigualdades que debe ser corregida: las desigualdades naturales. La injusticia en los dos casos parece similar puesto que las porciones distributivas no deberían ser influidas por factores arbitrarios desde el punto de vista moral. Así, si aquellos que tienen más aptitudes no merecen las ventajas que tienen, sus mayores expectativas serían legítimas sólo si se integran en un esquema que mejore las expectativas de los miembros menos favorecidos de la sociedad. ${ }^{57}$

Hay, con todo, una primera dificultad con esta postura, que podría presentarse del siguiente modo. La teoría de Rawls se expresa en términos de bienes primarios, esto es, aquellos bienes necesarios, sea cual sea la concepción del bien que uno tenga, como medios para perseguir nuestros fines. Rawls se aleja con esto por igual, tanto del utilitarismo, que centra la atención en el bienestar -y además exige maximización de un total o de un promedio entre la gente y no que las desigualdades maximicen las posiciones relativas a bienes primarios de quienes se encuentran en peor situación-, como del ideal de igualdad de oportunidades, que no corrige las desigualdades naturales. Sin embargo, Amartya Sen ha criticado los intentos de igualar a la gente en cuanto a sus niveles de bienestar como en sus niveles de recursos (ingresos o bienes primarios), proponiendo en su lugar el objetivo de igualar

\footnotetext{
${ }^{56}$ Cf. Rawls 1971:302-303.

${ }^{57}$ KyMLicKa puntualiza acertadamente que del hecho de que las desigualdades naturales y sociales sean arbitrarias podría seguirse que ese tipo de desigualdades deberían influir en la distribución sólo cuando redunden en beneficio de los que están peor. Pero el principio de diferencia dice que todas las desigualdades deben redundar en beneficio de los que están peor (cf. KYMLICKA 1990:72). No exploraré esta objeción.
} 
las capacidades básicas de la gente. ${ }^{58}$ La dificultad que apunta Sen con relación a una postura como la de Rawls es que su principio de la diferencia no le asigna más recursos a una persona discapacitada que a los otros en virtud de su discapacidad. Y ello porque la posición de los que están peor se caracteriza en términos de la posesión de bienes primarios sociales, sin considerar a tal fin las diferencias en bienes primarios naturales. En consecuencia, aun poseyendo los mismos bienes básicos, un discapacitado podría estar peor que otros con respecto a sus capacidades básicas y su bienestar. Un cierto nivel de ingresos puede sustentar diversas capacidades básicas, como la locomoción ordinaria para quienes no tienen discapacidades, pero no le conferirá las mismas capacidades a un ciego, por ejemplo, que necesita gastar una parte importante de sus ingresos para alimentar a su lazarillo. Se requiere de mayores ingresos para que una persona discapacitada alcance el mismo nivel de bienestar que alguien que no padece tal discapacidad. En conclusión, la igualdad de recursos no trata de manera adecuada las discapacidades. Es importante destacar que frente a este problema la solución no consiste en volver a tomar en cuenta niveles de bienestar, porque si bien desde este punto de vista se otorgarán mayores ingresos o recursos al discapacitado para que alcance el mismo nivel de bienestar que aquellos que no padecen discapacidades, también se le otorgarán mayores ingresos a quien posea gustos caros, ya que tanto unas como los otros resultan ineficientes para generar bienestar.

La dificultad para lidiar con las discapacidades no es la única de la teoría de Rawls. Un segundo problema relevante para la cuestión aquí examinada está dado por la legitimidad de los incentivos a los talentos. ¿Hay genuinas razones para aceptar que quienes resultan beneficiados naturalmente con ciertos talentos sean además recompensados con incentivos por ejercitarlos? ¿Está justificado que quien podría aportar algo para que muchos vivan mejor extorsione a la sociedad con no hacerlo si no recibe un privilegio por ello? Recuérdese que el principio de la diferencia admite que los

${ }^{58}$ Cf. Sen 1980. 
naturalmente privilegiados con ciertos talentos puedan recibir compensaciones económicas por poner en práctica tales talentos, siempre que sus acciones beneficien a quienes se encuentran peor. Pues bien, como lo ha puesto de manifiesto Gerald Cohen, si la idea básica de la Teoría de la justicia es neutralizar las desventajas que son producto de la suerte y, consiguientemente, que resultan moralmente arbitrarias, no se puede luego admitir por el mero hecho de que ello resulte superior paretianamente, que los talentosos obtengan mayores beneficios si los peor situados también se benefician de ello. ${ }^{59}$ Porque dicho análisis se concentra exclusivamente en una comparación con la situación inicial de máxima igualdad, sin tomar en consideración una alternativa de comparación que parece obviamente posible: una situación en la que la productividad sea igualmente alta pero donde no se consientan desigualdades, es decir, en la que los talentosos no reciban incentivos por ejercitar sus capacidades. Si el beneficiado con ciertos talentos no está dispuesto a ejercerlos sin ser recompensado, no es porque no pueda hacerlo sino porque no quiere hacerlo y, consiguientemente, nos está chantajeando, demostrando así su total falta de compromiso con la concepción de la justicia que se toma como base. ${ }^{60}$

Para concluir, sólo unas pocas palabras respecto de la postura de Ronald Dworkin. Pese a las críticas de Sen, Dworkin no se aparta de la idea de la igualdad de recursos, sino que ofrece una corrección al modo de concebirla: desde su punto de vista, las discapacidades pueden ser entendidas como recursos negativos. ${ }^{61}$ Sostiene que el igualitarismo de recursos debería entenderse en el sentido de buscar igualar a la gente con respecto a sus diferentes dotes naturales, pero no a sus diferentes ambiciones. Las

${ }^{59}$ Cf. Cohen 1992; Cohen 2000:168 y ss.

${ }^{60}$ Muchos autores han destacado que la versión que ofrece RAwLs de su teoría en Political Liberalism -o, si se quiere, la nueva teoría que allí presenta- agudiza sus aspectos desigualitarios, puesto que, por ejemplo, la idea del "overlapping consensus" no parece fácilmente congeniable con el principio de la diferencia (cf., entre otros, Williams 1993; BARRY 1995:913 y ss.).

${ }^{61}$ Los artículos en los que Dworkin desarrolló sus puntos de vista sobre la cuestión en los años ' 80 han sido compilados en DwORKIN 2000:parte I. 
¿Cómo puede el derecho obligar a quienes oprime?

preferencias de la gente reflejarían diferencias en las personas, mientras que los talentos y discapacidades resultarían meramente circunstanciales. Las diferencias atribuibles a la gente, tales como sus gustos caros, no serían afectadas, pero las que son atribuibles a sus diferentes circunstancias deberían ser corregidas. De este modo, Dworkin desarrolla su concepción, apoyada en esta distinción entre la gente y sus circunstancias, a través de la idea de un mercado de seguros hipotético en el que la gente puede asegurarse contra la posibilidad de resultar discapacitado, donde las primas de un seguro semejante permitirían determinar los pagos de impuestos que la gente debería efectuar. Esta concepción respetaría las diferentes preferencias de la gente entre una vida dedicada a la producción de riquezas y otra a disfrutar del ocio. ${ }^{62}$ Asimismo, si alguien eligiese una vida más riesgosa, en caso de que le vaya mal, la justicia no exigiría que se lo compense. Con todo, Roemer ha objetado que el corte de Dworkin entre una persona y sus circunstancias, entre ambiciones y dotes, se motiva en la idea de que la gente es responsable por sus preferencias, en la medida en que se identifica y está a gusto con ellas, con independencia de si fueron cultivadas voluntaria o involuntariamente. Pero Roemer duda de que la gente deba necesariamente ser considerada responsable sobre la base de sus preferencias, gustos y ambiciones. ${ }^{63} \mathrm{Si}$ alguien no es responsable por sus circunstancias, ¿por qué debería ser responsable por las preferencias que ha adoptado debido a ellas? No parece

\footnotetext{
${ }^{62}$ Tampoco resulta del todo claro que el trabajo justifique desigualdades económicas, y ello porque la línea divisoria entre trabajo y ocio no parece fácil de trazar (cf., por ejemplo, Arnsperger-VAn PariJs 2000:93). ¿Por qué quien trabaja más debe tener mejor posición económica que, por caso, quien dedica su vida a asistir a sus amigos? ¿Un operador de bolsa merece un mejor pasar que, por caso, Jesús de Nazareth, a quien hasta donde llegan mis conocimientos no se le conoce ningún trabajo lucrativo y que, como si fuera poco, predicaba que la gente debía desprenderse de sus riquezas? En realidad, no es el mayor trabajo sino, en todo caso, la mayor contribución a la cooperación social el criterio que se presupone aquí como legitimante de las desigualdades. Pero para ello necesitaríamos privilegiar una cierta concepción del bien sobre otras, lo que resulta incompatible con el liberalismo.

${ }^{63}$ Cf. Roemer 1996:capítulo 7.
} 
suficiente responder que ello es así porque se identifica con ellas y no habría elegido no tenerlas. ${ }^{64}$

Por supuesto, nada de lo que he dicho hasta aquí muy apretadamente puede reputarse un argumento concluyente para considerar que ninguna desigualdad económica resulta justificable. Pero sí para mostrar que ninguna de las justificaciones que cuentan con mayor fuerza intuitiva -ni la idea de derechos de propiedad irrevocables, ni la promoción de mayor bienestar, ni la mayor capacidad, ni el mayor beneficio para los peor situados, ni las elecciones libres, ni el mayor trabajo, ni una mayor contribución a la sociedadconstituye un camino libre de problemas para legitimar desigualdades. Se dirá que una sociedad de iguales es utópica. Sin ninguna duda. $\mathrm{O}$, al menos, con la misma certeza con la que puede afirmarse que concebir utopías es más valioso que pretender racionalizar nuestras vergüenzas.

${ }^{64}$ Sobre la base de un previo análisis del concepto de responsabilidad, Susan HuRLEY ha intentado demostrar que el objetivo de neutralizar la suerte no es apto para justificar el igualitarismo. Emplea diversos argumentos a tal fin, pero aquel al que aparentemente atribuye mayor peso es lo que denomina el dilema del neutralizador de la suerte (cf. HurLey 2003:155 y ss.). Lo que plantea este dilema es que la mala suerte puede interpretarse como una comparación interpersonal -mi situación es peor que la de otros-, o como una evaluación contrafáctica -mi situación es peor que como podría haber sido-. Bajo la primera interpretación, esta especificación de la igualdad resultaría trivial pues por definición no tendría mala suerte interpersonal si no estuviese peor que otros con relación a aquellos bienes que son cuestión de suerte. La igualdad sería, desde este punto de vista, tanto una cuestión de suerte como la desigualdad, de modo que el objetivo de neutralizar la mala suerte interpersonal no podría servir como justificación de la igualdad porque ello constituiría una petición de principio. Bajo la segunda interpretación, eliminar todos los mundos posibles mejores para mí o colocarme en el mejor de los mundos posibles para mí neutralizaría la mala suerte contrafáctica, pero hacer esto respecto de cada uno no tendría ninguna capacidad ni tendencia inherente para dejarnos a todos igualmente bien. Si partimos de situaciones desiguales, eliminar todos los mejores mundos posibles para cada uno nos dejaría en situación desigual, y el mejor mundo posible para mí podría ser mejor o peor que el de otros.

Estimo que la supuesta trivialidad que apunta HURLEY respecto de la primera de las alternativas consideradas no es tal y que, consiguientemente, el dilema puede solucionarse asumiendo su primer cuerno. Asimismo, la propuesta que defiende la propia HURLEY de que la justicia distributiva no debería fundarse en la neutralización de la suerte sino en la neutralización de "la influencia de creencias distorsionadas sobre lo que se debe hacer" me parece completamente desafortunada. No obstante, no intentaré aquí justificar ninguna de las dos cosas. 
¿Cómo puede el derecho obligar a quienes oprime?

\section{Referencias}

Arnsperger, Christian y Philippe VAn Pariss, Éthique économique et sociale,

Paris, Éditions La Découverte \& Syros, 2000.

BARRY, Brian, Justice and Impartiality, Oxford, Clarendon Press, 1995.

BAYÓN, Juan Carlos, La normatividad del derecho. Deber jurídico y razones

para la acción, Madrid, Centro de Estudios Constitucionales, 1991a.

BAYÓN, Juan Carlos, "Razones y reglas: sobre el concepto de 'razón

excluyente' en Joseph Raz", en Doxa - Cuadernos de filosofía del derecho, 10, 1991b, páginas 25-66.

BAYÓN, Juan Carlos, “¿Por qué es derrotable el razonamiento jurídico”, en

Doxa - Cuadernos de filosofía del derecho, 24, 2001, páginas 35-62.

Campbell, Tom, The Legal Theory of Ethical Positivism, Aldershot,

Dartmouth, 1996.

Caracciolo, Ricardo, El sistema jurídico. Problemas Actuales, Madrid, Centro de Estudios Constitucionales, 1988.

Cohen, Gerald, "Robert Nozick and Wilt Chamberlain: How Patterns Preserve Liberty”, en Erkenntis 11, 1977.

CoHen, Gerald, Self-Ownership, Freedom and Equality, Cambridge, Cambridge University Press, 1995.

Cohen, Gerald, "Incentives, Inequality, and Community", en The Tanner

Lectures on Human Values, vol. 13, Salt Lake City, University of Utah Press, 1992, páginas 263-329.

CoHen, Gerald, If You're an Egalitarian, How Come You're so Rich?,

Cambridge (Massachusetts) - London, Harvard University Press, 2000.

DANCY, Jonathan, Moral Reasons, Oxford, Blackwell, 1993.

DAVIDSON, Donald, Essays on Actions and Events, Oxford, Oxford University Press, 1980.

Dworkin, Ronald, Taking Rights Seriously, Cambridge, Mass., Harvard University Press, 1977.

Dworkin, Ronald, Sovereign Virtue. The Theory and Practice of Equality, 
Jorge L. Rodríguez

Cambridge (Massachusetts) - London, Harvard University Press, 2000. Dworkin, Ronald, "Hart's Postscript and the Character of Political Philosophy", en Oxford Journal of Legal Studies, Vol. 24, No 1, 2004, páginas 1-37.

Gargarella, Roberto, Las teorías de la justicia después de Rawls, Barcelona,

Paidós, 1999.

Gargarella, Roberto, "La última carta. El derecho de resistencia en situaciones de alienación legal", en Violencia y Derecho, SELA 2003, Buenos Aires, Editores del Puerto, 2004.

GeAch, Peter Tomas, Logic Matters, Oxford, Basil Blackwell, 1972.

HARE, Richard Mervin, Freedom and Reason, Oxford, Oxford University Press, 1963.

Hare, Richard Mervin, Sorting Out Ethics, Oxford, Oxford University Press, 1997, traducción castellana de J. V. Gifra, Reordenando la ética, Barcelona, Ariel, 1999.

Hart, H.L.A., The Concept of Law, Oxford, Clarendon Press, 1961, traducción castellana de G. Carrió, El concepto de derecho, Buenos Aires, Abeledo Perrot, 1963.

Hurley, Susan, Justice, Luck and Knowledge, Cambridge (Massachusetts) London, Harvard University Press, 2003.

Kymlicka, Will, Contemporary Political Philosophy, Oxford, Oxford University Press, 1990.

Lyons, David, Forms and Limits of Utilitarianism, Oxford, Oxford University Press, 1965.

MACKIE, John, "Rights, Utility and Universalization", en R. Frey, Utility and Rights, Minneapolis, University of Minnesota Press, 1984.

Martí, José Luis, Autogobierno deliberativo: una defensa de la democracia deliberativa participativa, tesis doctoral inédita, Barcelona, 2004.

Moreso, José Juan, "Dos concepciones de la aplicación de las normas de derechos fundamentales", manuscrito inédito, 2004.

Moreso, José Juan y Vilajosana José María, Introducción a la teoría del 
¿Cómo puede el derecho obligar a quienes oprime?

derecho, Madrid, Marcial Pons, 2004.

NAGEL, Thomas, "Nozick: Libertarianism Without Foundations", en Other Minds. Critical Essays 1969-1994, Oxford, Oxford Univesity Press, 1995.

NozIck, Robert, Anarchy, State and Utopia, New York, Basic Books Inc., 1974.

Nozick, Robert, The Examined Life. Philosophical Meditations, 1989, traducción al español de C. Gardini, Meditaciones sobre la vida, Barcelona, Gedisa, 1992.

Rawls, John, A Theory of Justice, Cambridge, Massachussets, Harvard University Press, 1971.

Rawls, John, Political Liberalism, New York, Columbia University Press, 1993.

Raz, Joseph, Practical Reasons and Norms, London, Hutchinson \& Sons Ltd, 1975.

Raz, Joseph, The Authority of Law: Essays on Law and Morality, Oxford, Clarendon Press, 1979.

RAz, Joseph, The Morality of Freedom, Oxford, Clarendon Press, 1986.

Redondo, María Cristina, "Razones y normas", en Revista Discusiones número V, Editorial EdiUNS, Bahía Blanca, 2005.

Roemer, John, Theories of Distributive Justice, Cambridge, Harvard University Press, 1996.

Sainsbury, R.M., Paradoxes, Cambridge, Cambridge University Press, 1995. Schauer, Frederick, Playing by the Rules. A Philosophical Examination of Rule-Based Decision-Making in Law and in Life, Oxford, Oxford University Press, 1991.

SEn, Amartya, Collective Choice and Social Welfare, San Francisco, HoldenDay, 1970.

SEn, Amartya, "Equality of What?", en The Tanner Lectures on Human Values, vol. 13, Salt Lake City, University of Utah Press, 1980, páginas 197-220. 
Jorge L. Rodríguez

Sen, Amartya, Inequality Reexamined, Oxford, Oxford University Press, 1992.

WALDRON, Jeremy, "Normative (or Ethical) Positivism", en Jules Coleman (ed.), Hart's Postscript. Essays on the Postcript to The Concept of Law, Oxford, Oxford University Press, 2001, páginas 410-434.

Williams, Bernard, "Review of John Rawls Political Liberalism", en London Review of Books, $n^{\circ} 13,1993$, página 8.

Zuleta, Hugo, Razón y elección, México, Fontamara, 1998. 